\title{
Numerical modelling of the cooling effect in geothermal reservoirs induced by injection of $\mathrm{CO}_{2}$ and cooled geothermal water
}

\author{
Hejuan $\mathrm{Liu}^{1,2,{ }^{*}}$, Qi Li ${ }^{1,2}$, Yang Gou ${ }^{3}$, Liwei Zhang ${ }^{1,2}$, Wentao Feng ${ }^{3}$, Jianxing Liao ${ }^{3}$, Zhengwen Zhu ${ }^{4}$, \\ Hongwei Wang ${ }^{5}$, and Lei Zhou ${ }^{6}$ \\ ${ }^{1}$ State Key Laboratory of Geomechanics and Geotechnical Engineering, Institute of Rock and Soil Mechanics, \\ Chinese Academy of Sciences, 430071 Wuhan, PR China \\ ${ }^{2}$ University of Chinese Academy of Sciences, 100049 Beijing, PR China \\ ${ }^{3}$ Energie-Forschungszentrum Niedersachsen, Clausthal University of Technology (TUC), Am Stollen 19A, 38640 Goslar, Germany \\ ${ }^{4}$ School of Geoscience and Technology, Southwest Petroleum University, 610500 Chengdu, PR China \\ ${ }^{5}$ College of Energy, Chengdu University of Technology, 610059 Chengdu, PR China \\ ${ }^{6}$ State Key Laboratory of Coal Mine Disaster Dynamics and Control, Chongqing University, 400030 Chongqing, PR China
}

Received: 14 May 2019 / Accepted: 21 January 2020

\begin{abstract}
The utilization of geothermal energy can reduce $\mathrm{CO}_{2}$ emissions into the atmosphere. The reinjection of cooled return water from a geothermal field by a closed loop system is an important strategy for maintaining the reservoir pressure and prolonging the depletion of the geothermal reservoir by avoiding problems, e.g., water level drawdown, ground subsidence, and thermal pollution. However, the drawdown of water injectivity affected by physical and chemical clogging may occur in sandstone aquifers, and the reservoir temperature may be strongly affected by the reinjection of large amounts of cooled geothermal water, thus resulting in early thermal breakthrough at production wells and a decrease in production efficiency. In addition to the injection of cooled geothermal water, the injection of $\mathrm{CO}_{2}$ can be used to maintain the reservoir pressure and increase the injectivity of the reservoir by enhancing water-rock interactions. However, the thermal breakthrough and cooling effect of the geothermal reservoir may become complex when both $\mathrm{CO}_{2}$ and cooled geothermal water are injected into aquifers. In this paper, a simplified small-scale multilayered geological model is established based on a low-medium geothermal reservoir in Binhai district, Tianjin. The ECO2N module of the TOUGH2MP simulator is used to numerically simulate temperature and pressure responses in the geothermal reservoir while considering different treatment strategies (e.g., injection rates, temperatures, well locations, etc.). The simulation results show that a high injection pressure of $\mathrm{CO}_{2}$ greatly shortens the $\mathrm{CO}_{2}$ and thermal breakthrough at the production well. A much lower $\mathrm{CO}_{2}$ injection pressure is helpful for prolonging hot water production by maintaining the reservoir pressure and eliminating the cooling effect surrounding the production wells. Both pilot-scale and commercial-scale cooled water reinjection rates are considered. When the water production rate is low $(2 \mathrm{~kg} / \mathrm{s})$, the temperature decrease at the production well is negligible at a distance of $500 \mathrm{~m}$ between two wells. However, when both the production and reinjection rates of cooled return water are increased to $100 \mathrm{~m}^{3} / \mathrm{h}$, the temperature decrease in the production well exceeds $10^{\circ} \mathrm{C}$ after 50 years of operation.
\end{abstract}

Nomenclature
$\begin{array}{ll}C_{r} & \text { Specific heat of the rock }\left(\mathrm{J} /\left(\mathrm{kg}{ }^{\circ} \mathrm{C}\right)\right) \\ H & \text { Heat accumulation amount }\left(\mathrm{J} / \mathrm{m}^{3}\right) \\ k & \text { Permeability }\left(\mathrm{m}^{2}\right) \\ k_{r l} & \text { Relative liquid permeability }(-) \\ k_{r g} & \text { Relative gas permeability }(-) \\ P & \text { Pore pressure }(\mathrm{Pa}) \\ S & \text { Saturation }\end{array}$

* Corresponding author: hjliu@whrsm.ac.cn

\author{
Temperature $\left({ }^{\circ} \mathrm{C}\right)$ \\ Mass fraction $(-)$ \\ Specific internal energy in liquid phase $(\mathrm{J} / \mathrm{kg})$ \\ Specific internal energy in gas phase $(\mathrm{J} / \mathrm{kg})$ \\ Porosity (-) \\ Density $\left(\mathrm{kg} / \mathrm{m}^{3}\right)$ \\ Rock grain density $\left(\mathrm{kg} / \mathrm{m}^{3}\right)$ \\ Viscosity (Pa s) \\ Superscript water component \\ Superscript $\mathrm{CO}_{2}$ component \\ Subscript liquid phase
}


g Subscript gas phase

$s \quad$ Subscript solid phase

\section{Introduction}

Since the winter of 2013, more than 30 provinces in China have experienced very serious air pollution termed "haze". To control this air pollution, the following measures have been implemented: modifying the energy consumption structure; reducing the consumption of coal, which releases large amounts of $\mathrm{CO}_{2}, \mathrm{SO}_{x}$ and dust into the atmosphere; and greatly increasing the proportion of renewable energy in the energy consumption structure [1]. The enthusiasm for the extraction of low-medium enthalpy geothermal resources is motivated by the successful geothermal source district heating system in Xiongxian, which is located $130 \mathrm{~km}$ from Beijing. More than $92 \%$ of the district heating systems are driven by geothermal hot water with temperatures less than $90^{\circ} \mathrm{C}[2]$. China has abundant low-medium enthalpy hydrothermal reservoirs at shallow depths. If the type of low-medium enthalpy geothermal source district heating system applied in Xiongxian and Tianjin can be copied and widely applied in other regions of China, the air quality can be improved because of the decrease in traditional coal-based thermal power plants.

The overexploitation of hot water from subsurface reservoirs may result in land subsidence and thermal and chemical pollution if the cooled geothermal tail-water is not treated properly and discharged directly into the ground [3-5]. The reinjection of recycled geothermal water is an important strategy for maintaining reservoir pressures, prolonging the depletion of geothermal reservoirs, and efficiently avoiding problems, such as ground subsidence and heat and chemical pollution of the environment. Considering the history of cooled geothermal reinjection worldwide, France generated the first doublet system with one reinjection well and one production well in the geothermal reservoir located at Melun l'Almont geothermal field in 1969. The geyser is known for having not only the largest geothermal power station worldwide but also a mature reinjection system that has been reinjecting the waste water near the geothermal field into the subsurface high-temperature geothermal reservoir to maintain its pore pressure since 1997. Germany also has many successful experiences with reinjecting waste water into geothermal reservoirs, e.g., Waren and Neubrandenburg, with a reinjection rate of $50 \mathrm{~m}^{3} / \mathrm{h}$ [6]. Reinjecting cooled geothermal water into fractured carbonates, volcanic debris, and consolidated sandstones is easier than reinjecting this water into loose porous sandstone reservoirs because of the clogging problems caused by physical and chemical effects $[7,8]$. Many numerical and experimental studies focus on the reinjection efficiency, which is affected by factors, including the characteristics of the geological formations at the macroscale, such as the stratigraphic configuration and fracture distribution system, and at the microscale, such as the porosity, permeability, and pore and grain distributions [6]. In addition, the reinjection strategy, including the pressure, temperature, and reinjection rate, has a great impact on the efficiency of the reinjection operation $[9,10]$.

In addition to the reinjection of pure water to maintain stable reservoir pressure, $\mathrm{CO}_{2}$ has been considered for injection into geothermal reservoirs in both $\mathrm{H}_{2} \mathrm{O}$-based and $\mathrm{CO}_{2}$-based strategies in recent studies [11-24]. $\mathrm{CO}_{2}$-Aided Geothermal Systems ( $\mathrm{CO}_{2}$-AGES) are helpful for maintaining the reservoir pressure and present much higher flow rates than water systems, thus extracting more heat $[9,19]$. Some geothermal reservoirs are initially rich in $\mathrm{CO}_{2}$ dissolved in geothermal fluids [21]. For instance, to generate $1 \mathrm{kWh}$ electricity, the $\mathrm{CO}_{2}$ emission amount can reach $0.9-1.8 \mathrm{~kg}$ in most geothermal fields in Turkey. If $\mathrm{CO}_{2}$ is emitted into the atmosphere, the geothermal reservoir will be depleted in the long term. The injection of $\mathrm{CO}_{2}$ into the geothermal reservoir can maintain its pressure, generate an artesian flow of brine and increase the storage capacity of $\mathrm{CO}_{2}$ by generating a large amount of space induced by hot water extraction. This type of geothermal energy extraction with the help of $\mathrm{CO}_{2}$ injection can actually be regarded as energy storage in a sedimentary basin [22-24]. A pilot-scale injection of $\mathrm{CO}_{2}$ combined with cooled degassed injectate lasted for a period of two months in the Umurlu geothermal field in Turkey between October and December of 2017, highlighting the profound effect of injection on the behavior of reservoir pressure surrounding the production wells close to the injection wells [21]. In addition, the injection of $\mathrm{CO}_{2}$ into a geothermal reservoir can increase the porosity and permeability by strengthening the water-rock interactions [24], thus potentially improving the geothermal reinjection efficiency of cooled geothermal return water in sandstone reservoirs.

A negative impact of fluid reinjection is the associated obvious temperature decline or cooling effect in the reservoir $[25,26]$. Furthermore, the temperature decline may last for a long time before heat recovery, strongly affecting the long-term production of geothermal energy. The injection of $\mathrm{CO}_{2}$ may cause a much more complex cooling effect in the geothermal reservoir because thermal breakthrough highly depends on the geological structure of the geothermal reservoir, which controls the mode of fluid transport and flow-channel/fracture-space characteristics [27, 28]. However, few studies showing the cooling effects in geothermal reservoirs by comparing the simultaneous or separate injection of cold $\mathrm{CO}_{2}$ and cooled geothermal return water are available. The injection of $\mathrm{CO}_{2}$ and water into either the same or different layers of aquifers may cause a cooling effect surrounding the production region if poorly organized. Thus, the careful design of the injectionproduction-reinjection well configuration should be tested for the development of $\mathrm{CO}_{2}$-aided geothermal energy extraction systems.

In this paper, a small-scale simplified, idealistic geological model is established based on the Guantao formation and its overlying and underlying formations in Binhai district in Tianjin. A comparison of the cooling effects in the geothermal reservoir (e.g., Guantao formation) caused by the injection of $\mathrm{CO}_{2}$ and cooled geothermal return water is performed by numerical methods. The goal of the preliminary study reported in this paper is to provide a 
general understanding of the pressure and temperature response of the geothermal reservoir when using this type of injection-production system. Sensitivity studies are carried out while considering different injection/production rates, temperatures, boundary conditions, well configurations, etc. A basic understanding of how to control the cooling effect in a multilayered reservoir-caprock system is essential before an optimized injection-productionreinjection system is established in a large-scale geothermal reservoir.

\section{Exploitation of geothermal energy in Tianjin}

The Bohaiwan basin, especially the Huabei plain, is characterized by rich hydrothermal resources [29] with a geothermal water reserve of approximately $1.3 \times 10^{13} \mathrm{~m}^{3}$. The successful utilization of hydrothermal resources has been widely applied in district heating systems in regions, including Tianjin, Beijing, and parts of Hebei province (e.g., Xiongxian). Hot water at a low-medium temperature is extracted from several formations (Tab. 1) in Bohaiwan basin from top to bottom, including the Minghuazhen formation $\left(N_{m}\right)$, Guantao formation $\left(N_{g}\right)$, Dongying formation $\left(E_{d}\right)$, and Wumishan formation $\left(J_{w}\right)$. Most hot water-bearing formations are also rich in oil. The main productive layer of the Gudao oilfield is the Guantao formation, while the main productive layers of the Shuguang and Shengli oilfields are $E_{S}^{1+3}$ and $E_{S}^{2+3}$, respectively (Tab. 2). In addition to the rich geothermal resources in Bohaiwan basin, many other oilfields have been discovered and exploited, especially in the Jizhong depression zone (Fig. 1), including the buried hill oil reservoir in Wumishan carbonates represented by the Renqiu oilfield. The temperature of the Renqiu oil reservoir ranges from $110{ }^{\circ} \mathrm{C}$ to $125{ }^{\circ} \mathrm{C}$ with a geothermal gradient of $1.7-1.8^{\circ} \mathrm{C} / 100 \mathrm{~m}$. In addition, the Chaheji oilfield, which is characterized as an $E_{d}^{3}-E_{s}^{1}$ fluvial sandstone reservoir, is the largest Tertiary oilfield.

Geothermal energy has been utilized in district heating systems in China since 1990, and the covered area greatly increased to 88.75 million $\mathrm{m}^{2}$ by 2016 (Fig. 2). Tianjin is

Table 1. Cenozoic strata lithology and fluid production status in Tianjin.

\begin{tabular}{|c|c|c|c|c|}
\hline System & $\begin{array}{l}\text { Formations and } \\
\text { thickness }\end{array}$ & Section & Lithology & Production status \\
\hline Quaternary & $Q(-)$ & & $\begin{array}{l}\text { Mudstone, sandy mudstone, } \\
\text { and sandstone }\end{array}$ & Industrial oil flows \\
\hline \multirow[t]{2}{*}{ Neogene } & $N_{2} m(600-1000 \mathrm{~m})$ & $\begin{array}{l}\text { Upper } \\
\text { Lower }\end{array}$ & $\begin{array}{l}\text { Fine siltstone, sandstone, and } \\
\text { mudstone }\end{array}$ & $\begin{array}{l}\text { Hot water extraction layer with } \\
\text { water flow rates of } 40-100 \mathrm{~m}^{3} / \mathrm{h} \text { and } \\
T=40-80{ }^{\circ} \mathrm{C}\end{array}$ \\
\hline & $N_{1} g(300-900 \mathrm{~m})$ & $\begin{array}{l}N_{1} g^{1} \\
N_{1} g^{2} \\
N_{1} g^{3}\end{array}$ & $\begin{array}{l}\text { Medium-coarse sandstone } \\
\text { interlayered with mudstone }\end{array}$ & $\begin{array}{l}\text { Main geothermal reservoir with } \\
\text { water extraction rates of } \\
80-130 \mathrm{~m}^{3} / \mathrm{h} \text { and } T=48-82{ }^{\circ} \mathrm{C}\end{array}$ \\
\hline \multirow[t]{3}{*}{ Paleogene } & $E_{3} d(100-800 \mathrm{~m})$ & $\begin{array}{l}E_{3} d^{1} \\
E_{3} d^{2} \\
E_{3} d^{3}\end{array}$ & $\begin{array}{l}\text { Mudstone interlayered with } \\
\text { sandstone and gravel-bearing } \\
\text { sandstone }\end{array}$ & $\begin{array}{l}\text { Wellhead flowing rates of } \\
40-80 \mathrm{~m}^{3} / \mathrm{h} \text { and wellhead flowing } \\
T=78-93{ }^{\circ} \mathrm{C}\end{array}$ \\
\hline & & $E_{s}^{2}$ & $\begin{array}{l}\text { Upper part is sandstone } \\
\text { interlayered with mudstone; } \\
\text { lower part is carbonaceous } \\
\text { shales and sandstones }\end{array}$ & $\begin{array}{l}\text { Industrial oil flows, e.g., in Shengli } \\
\text { oilfield }\end{array}$ \\
\hline & & $E_{s}^{3}$ & $\begin{array}{l}\text { Sandstone interlayered with } \\
\text { mudstone and oil shale }\end{array}$ & $\begin{array}{l}\text { Industrial oil flows, e.g., in Shengli } \\
\text { oilfield and Shuguang oilfield }\end{array}$ \\
\hline
\end{tabular}


Table 2. Reservoir thermal properties of the Guantao formation located in the Huanghua depression and Cangxian uplift zone in Tianjin [6].

\begin{tabular}{lcc}
\hline Thermal property parameters & Cangxian uplift & Huanghua depression zone \\
\hline Top boundary $(\mathrm{m})$ & $1112-1522$ & $1152-1788$ \\
Bottom boundary $(\mathrm{m})$ & $1137-2277$ & $1278-2847$ \\
Thickness $(\mathrm{m})$ & $24-755$ & $126-1059$ \\
Thickness ratio of sandstone and mudstone layer & $0.21-0.64$ & $0.55-0.64$ \\
Porosity $(\%)$ & $18-36.6$ & $31.5-36.6$ \\
Permeability coefficient $(\mathrm{m} / \mathrm{d})$ & $0.67-1.27$ & $0.37-1.71$ \\
Fluid temperature at the wellhead $\left({ }^{\circ} \mathrm{C}\right)$ & $45-81$ & $42-78$ \\
Water production rate $\left(\mathrm{m}^{3} / \mathrm{h}\right)$ & $40-60$ & $80-120$ \\
Chemistry of the fluid & $\mathrm{HCO}_{3}-\mathrm{Cl}-\mathrm{Na}$ & $\mathrm{HCO}_{3}-\mathrm{Na}^{-} \mathrm{HCO}_{3}-\mathrm{Cl}-\mathrm{Na}$ \\
& $\mathrm{SO}-\mathrm{Cl}-\mathrm{Na}$ & $1-1.9$ \\
TDS $(\mathrm{g} / \mathrm{L})$ & $1-6$ & $1-6$ \\
\hline
\end{tabular}

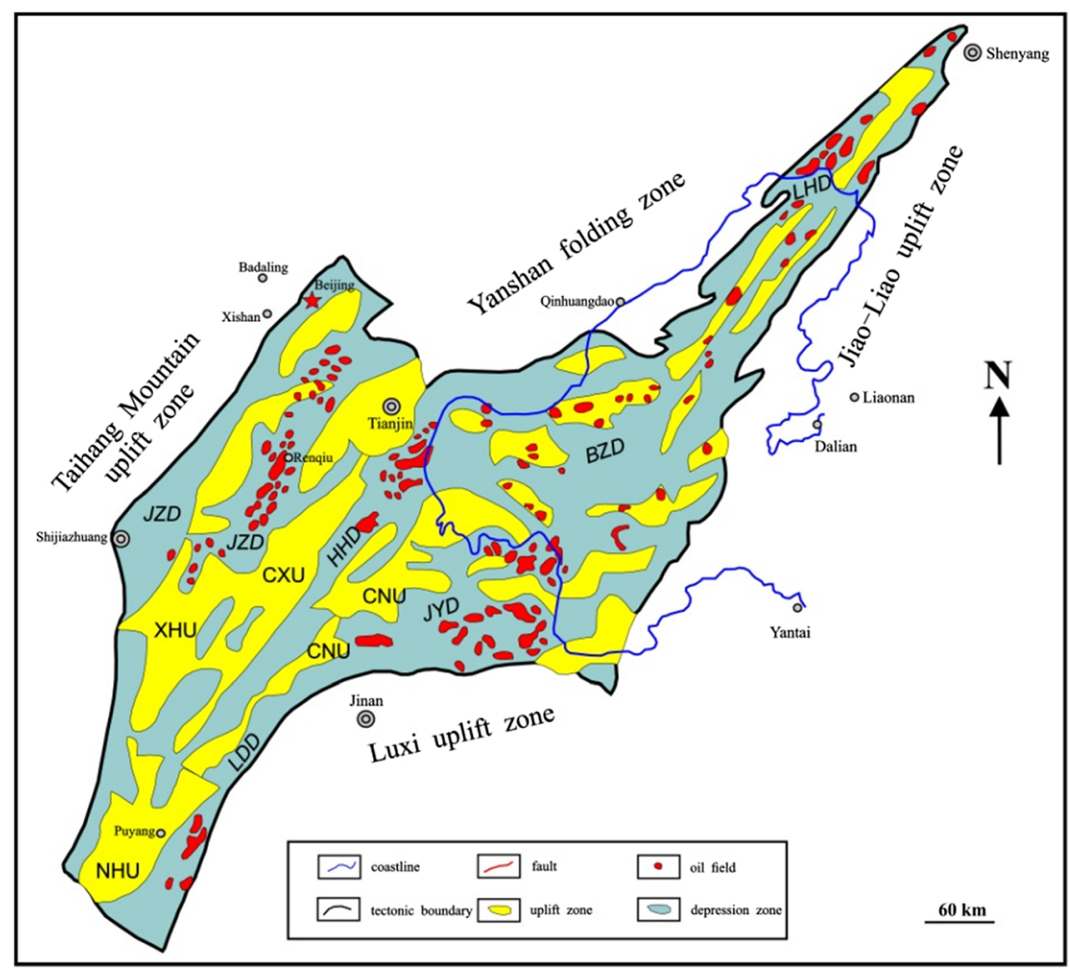

Fig. 1. Simplified tectonic framework of the depression-uplift zones in Bohaiwan basin (modified from [29]) and the location of Tianjin.

famous for its successful geothermal utilization, especially through the geothermal direct heating system, currently covering a total area of 22.33 million $\mathrm{m}^{2}$. At the end of 2013, its geothermal direct heating system reached an area of 20 million $\mathrm{m}^{2}$ with 474 geothermal production wells [30]. Its proportion was approximately $50 \%$ of China's total geothermal direct heating systems in 2009 with a heating area of 12.13 million $\mathrm{m}^{2}$, including 264 production wells and 53 reinjection wells with a reinjection ratio of only $24.5 \%$. The sandstone aquifers of the Guantao formation $\left(N_{1} g\right)$, karst/fractured carbonate reservoirs of the Ordovician and Wumishan (Jxw), and Cambrian formations are used to extract hot water in Tianjin [27, 28]. The maximum drilling depth is more than $4000 \mathrm{~m}$, and the maximum discharge rate of a single well is more than $100 \mathrm{~m}^{3} / \mathrm{h}[28]$. However, the long-term extraction of subsurface hot water has resulted in a serious decrease in the groundwater level and subsidence in Tianjin. The reinjection of cooled geothermal return water into production aquifers controls subsidence to some extent, although most parts of Tianjin still have a subsidence rate of $10-40 \mathrm{~mm} /$ year [31]. 


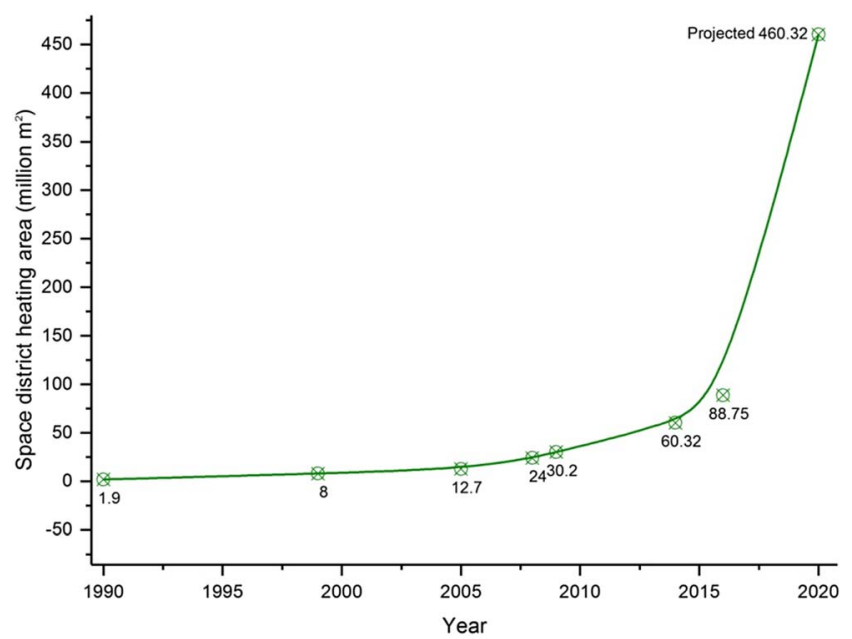

Fig. 2. Utilization of geothermal energy in the district heating system between 1990 and 2020 in China.

As a successful model of geothermal energy utilization in China, studies investigating the reinjection technology of Tianjin began in the 1980s, and many valuable improvements, such as in the equipment used in the reinjection technology, well completion technology, etc., have been achieved. Reinjection has efficiently inhibited the water level drawdown and subsidence in the Tianjin geothermal system to some degree [31, 32]. The maximum reinjection rate in Tianjin in the sandstones of the Guantao formation reaches $100-120 \mathrm{~m}^{3} / \mathrm{h}$. The reinjection of cooled geothermal water is useful for maintaining the reservoir pressure. However, if the reinjection wells are located close to production wells or the reinjection amount is greatly increased, the cooled reinjection fluid will cause a cooling effect on the geothermal reservoir, and the water from the production wells will be rapidly cooled and impacted by the thermal breakthrough [31,33]. This phenomenon is common not only in deep hydrothermal reservoirs but also hot dry rocks [34].

The reinjection ratio (i.e., the ratio between the reinjection and production amounts of geothermal water) in Tianjin greatly varies. Based on statistical data, the reinjection ratio was as high as $63 \%$ in 2000, while it was as low as $24.5 \%$ in 2009 . Additionally, large differences exist in the reinjection ratios of different geothermal reservoirs [30]. The karstic carbonate reservoirs of the Ordovician have the largest reinjection ratio of $114.87 \%$, followed by the Cambrian geothermal reservoirs at $66.61 \%$ and the Wumishan formation at $47.4 \%$, while the sandstone reservoirs of the Guantao formation have a much lower reinjection ratio of $9.9 \%$. Minghuazhen $\left(N_{2} m\right)$ had a very limited reinjection amount of return water, and there was no reinjection activity in the Dongying $\left(E_{3} d\right)$ formation (see Fig. 3). The Guantao formation plays a great role in producing $19 \%$ of Tianjin's hot geothermal water. A lower reinjection ratio of geothermal water may result in the depletion of reservoir pressure over the long term. Therefore, more fluid needs to be injected into its production layer to increase the reservoir pressure and inhibit continuous subsidence [35].

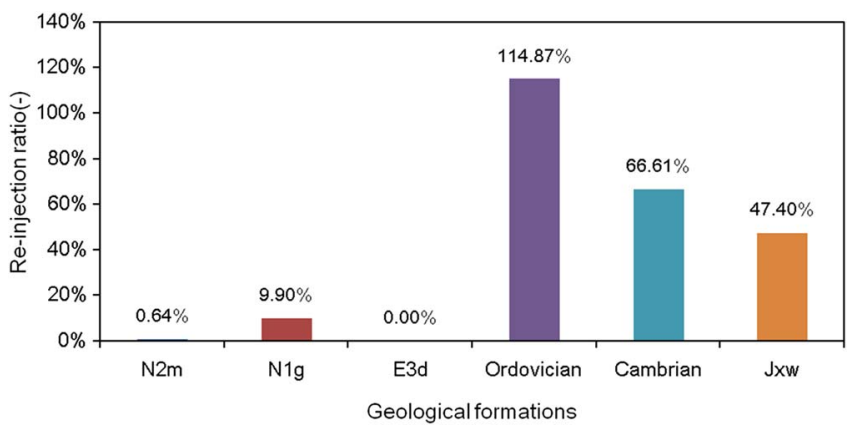

Fig. 3. Reinjection ratios in different geothermal reservoirs in Tianjin between 1997 and 2013.

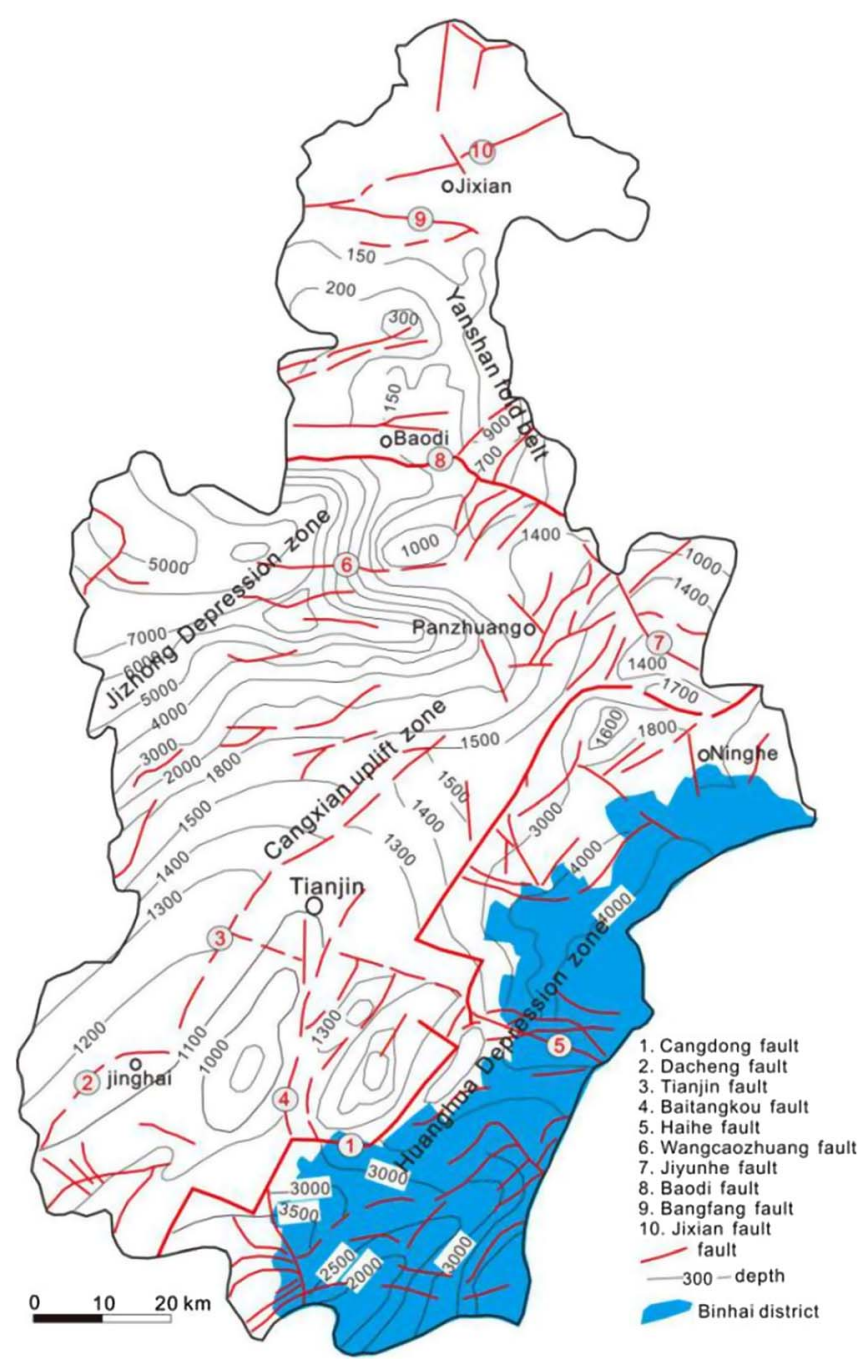

Fig. 4. Bottom depth of the Cenozoic group and the distribution of the fault system in Tianjin, especially in Binhai district (modified based on [35]).

Tianjin is characterized by very thick Cenozoic group formations (more than $4000 \mathrm{~m}$ ) in some regions, e.g., in the Binhai district, which belongs to the Huanghua depression zone (Fig. 4). The bottom depth of the Guantao 
formation is located at a depth of 990-2660 m. In the Cangxian uplift zone, the thickness of the Guantao formation is thin, and the buried depth is shallow. Far from the uplift zone, the buried depth is deep, and the thickness of the formation increases. The top depth of the Guantao formation in the Huanghua depression ranges between 1152 and $1788 \mathrm{~m}$ with a thickness of 126-1059 m [6]. The detailed reservoir thermal properties of the Huanghua depression and Cangxian uplift zone in the Guantao formation are listed in Table 2.

In Binhai district, the geothermal reserve is $6.28 \times 10^{19} \mathrm{~J}$, and the annual reserves of hot water in the Guantao formation can reach $1.15 \times 10^{7} \mathrm{~m}^{3}[36]$. The fluid temperature at the wellhead, which is produced from the Guantao formation, is $45-78{ }^{\circ} \mathrm{C}$, and the water chemistry shows that the water is $\mathrm{HCO}_{3}-\mathrm{Na}$ and $\mathrm{HCO}_{3}-\mathrm{Cl}-\mathrm{Na}$ with TDS (total dissolved solids) values ranging from $0.8 \mathrm{~g} / \mathrm{L}$ to $1.9 \mathrm{~g} / \mathrm{L}$. The temperature gradient ranges from 2.5 to $3.0^{\circ} \mathrm{C} / 100 \mathrm{~m}$ [30]. The permeability is less than $50 \mathrm{mD}$, the permeability coefficient is $0.3-2.2 \mathrm{~m} / \mathrm{d}$, the transmission coefficient is $40-212 \mathrm{~m}^{2} / \mathrm{d}$, and the porosity is $18-36.6 \%$. Based on production and reinjection data from Binhai district in Tianjin in 2013, there are 85 production wells with a total annual hot water production of 3.866 million $\mathrm{m}^{3}$ (i.e., $1.44 \mathrm{~kg} / \mathrm{s} /$ well) and 14 reinjection wells with an annual reinjection amount of $28.8 \times 10^{4} \mathrm{~m}^{3}$ (i.e., $0.65 \mathrm{~kg} / \mathrm{s} /$ well).

\section{Numerical model setup and parameterizations}

\subsection{Mathematical equations}

Generally, the injection of $\mathrm{CO}_{2}$ and the reinjection of cooled geothermal water into geothermal reservoirs are multiphase, multicomponent, and nonisothermal problems. Therefore, a mass conservation function involving two phases (gas and liquid) is used to describe the fluid flow in a porous or fractured medium. Using the water component as an example, the governing equation is stated as follows:

$$
\begin{aligned}
& \frac{\partial}{\partial x}\left(\phi\left(X_{l}^{w} S_{l} \rho_{l}+X_{g}^{w} S_{g} \rho_{g}\right)\right)= \\
& -\nabla \times\left\{X_{l}^{w} \rho_{l}\left(-k \frac{k_{r l}}{\mu_{l}}\left(\nabla P_{l}-\rho_{l} g\right)\right)\right. \\
& \left.+X_{g}^{w} \rho_{g}\left(-K \frac{k_{r g}}{\mu_{g}}\left(\nabla P_{g}-\rho_{g} g\right)\right)\right\}+\left(q_{l}^{w}+q_{g}^{w}\right),
\end{aligned}
$$

where $S$ represents the saturation $(-), X$ is the mass fraction $(-), \phi$ is the porosity $(-), \rho$ is the density $\left(\mathrm{kg} / \mathrm{m}^{3}\right), \mu$ is the viscosity (Pa s), $k$ is the permeability $\left(\mathrm{m}^{2}\right), k_{r l}$ represents the relative liquid permeability $(-), k_{r g}$ represents the relative gas permeability $(-), P$ is the pore pressure $(\mathrm{Pa})$, superscript $w$ represents water, $l$ is the liquid phase, and $g$ is the gas phase.

Regarding the $\mathrm{CO}_{2}$ component, the governing equations of mass conservation are rewritten as follows:

$$
\begin{aligned}
& \frac{\partial}{\partial x}\left(\phi\left(X_{l}^{c} S_{l} \rho_{l}+X_{g}^{c} S_{g} \rho_{g}\right)\right)=-\nabla \times\left\{X_{l}^{c} \rho_{l}\left(-k \frac{k_{r l}}{\mu_{l}}\left(\nabla P_{l}-\rho_{l} g\right)\right)\right. \\
& \left.\quad+X_{g}^{c} \rho_{g}\left(-k \frac{k_{r g}}{\mu_{g}}\left(\nabla P_{g}-\rho_{g} g\right)\right)\right\}+\left(q_{l}^{c}+q_{g}^{c}+q_{s}^{c}\right), \quad(2)
\end{aligned}
$$

where superscript $c$ indicates $\mathrm{CO}_{2}$, and subscript $s$ indicates the solid phase.

Similarly, the Heat $(H)$ accumulation in the two-phase system is described as follows:

$$
H=(1-\phi) \rho_{r} C_{r} T+\phi\left(S_{l} \rho_{l} u_{l}+S_{g} \rho_{g} u_{g}\right)
$$

where $\rho_{r}$ represents the rock grain density $\left(\mathrm{kg} / \mathrm{m}^{3}\right), C_{r}$ is the specific heat of the rock $\left(\mathrm{J} /\left(\mathrm{kg}{ }^{\circ} \mathrm{C}\right)\right), T$ is the temperature $\left({ }^{\circ} \mathrm{C}\right), u_{l}$ is the specific internal energy in the liquid phase $(\mathrm{J} / \mathrm{kg})$, and $u_{g}$ is the specific internal energy in the gas phase $(\mathrm{J} / \mathrm{kg})$.

\subsection{Geological model setup and mesh discretization}

A small-scale, simplified geological model is established based on the geology of the Guantao formation and its overlying and underlying layers in Binhai district in Tianjin (see the detailed description in Sect. 2). The geometry of this model is used as the geometry (with dimensions of $3000 \mathrm{~m}, 1500 \mathrm{~m}, 700 \mathrm{~m}$ in the $x, y$, and $z$ directions, respectively) of the numerical model, which aims to analyze the pressure and temperature responses caused by injection of cooled geothermal water and $\mathrm{CO}_{2}$ to realize the optimization of the well configuration and strategies concerning the injection and production rates, pressure, temperature, etc. The scheme of the $X Z$ geological section along with the multilayered reservoir-caprock configuration is shown in Figure 5. The top of the model is set at a depth of $1800 \mathrm{~m}$, and the bottom depth is $2500 \mathrm{~m}$. The total thickness of the model is $540 \mathrm{~m}$, while the thickness of the caprock is $160 \mathrm{~m}$. Based on the geological description of Binhai district in Tianjin, aquifer 2, which has a thickness of $500 \mathrm{~m}$, can be used to represent the Guantao formation. Considering that cooled tail water can be injected into a different layer far from the production formation to avoid early thermal breakthrough in many geothermal engineering situations (e.g., Mori, Bardy, etc.) [37], a hetero-layered "two production wells and two reinjection wells" configuration mode is applied in this study, and another well is designed for $\mathrm{CO}_{2}$ injection. The geothermal production wells are completed in highly permeable aquifers, and two cooled geothermal water reinjection wells are placed in the upper layer as shown in Figure 5. This type of well configuration is used to avoid thermal breakthrough caused by cooled geothermal water injection. Thus, the impacts of $\mathrm{CO}_{2}$ injection on the reservoir pressure and temperature can be studied in detail. The well spacing is assumed to be $500 \mathrm{~m}$ in the $X$ direction. The discretization of the meshes is fine near the wells, and the meshes become progressively coarser as the distance from the wells increases. In total, there are 52500 meshes $\left(N_{x}=50, N_{y}=30, N_{z}=35\right)$ in the numerical model. 


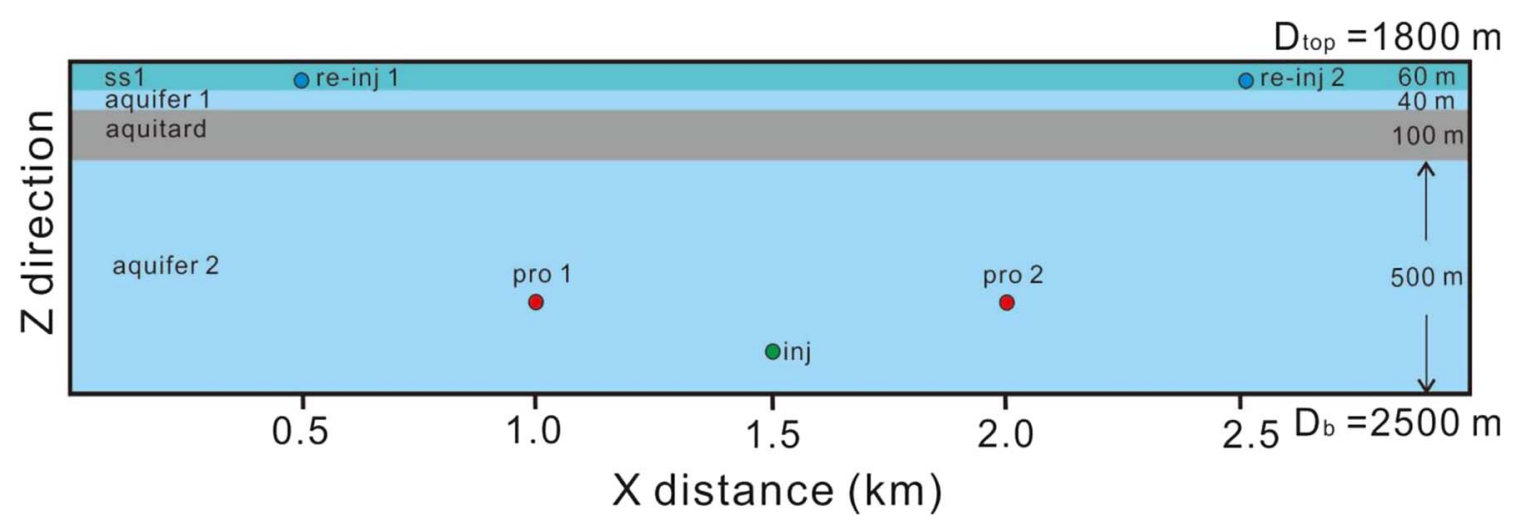

Fig. 5. Schematic multilayered aquifer-aquitard system in the $X Z$ section representing a local region of Binhai district in Tianjin.

\subsection{Input parameters in the numerical model}

The ECO2N module of the parallel simulator TOUGH2MP is applied to simulate the cooling effect in the geothermal reservoir induced by geothermal water production and fluid injection [9]. Three components (water, $\mathrm{NaCl}$, and $\mathrm{CO}_{2}$ ) are considered, and the pressure range is less than $60 \mathrm{MPa}$ with temperatures ranging from $10{ }^{\circ} \mathrm{C}$ to $110{ }^{\circ} \mathrm{C}$. The reservoir pressure and temperature in low-medium enthalpy geothermal reservoirs in Binhai district in Tianjin are in the applicable range of the ECO2N module. The capillary pressure function is described by Van Genuchten [38], and the relative permeabilities of liquid and gas are described by Van Genuchten [38] and Corey [39], respectively.

\subsubsection{Hydrogeological properties of geothermal reservoirs}

Table 3 summarizes the parameters, including the hydrogeological properties of the aquifer and aquitard formations (e.g., porosity, permeability, thickness, density, and thermal conductivity), initial and boundary conditions of the numerical model, and the strategies of injection, production, reinjection, etc., involved in the simulation study of the base case representing low rates of geothermal water production and reinjection. The porosity is set as 0.3 and 0.1 for the aquifer and aquitard, respectively. Accordingly, the permeability of the aquifer is assumed to be $50 \mathrm{mD}$, while that of the aquitard is assumed to be $0.001 \mathrm{mD}$. It is assumed that the siltstone reservoir is used to store the cooled geothermal reinjection water and that its porosity and permeability are low. The parameters of the geological formations used in the base case are determined based on data obtained from the Guantao formation in Tianjin.

\subsubsection{Initial and boundary conditions}

The initial pore pressure is set as the hydrostatic pressure. The conservative estimation of the geothermal gradient is $25^{\circ} \mathrm{C} / \mathrm{km}$, and the salinity of the fluid in the reservoir is defined as $1.8 \mathrm{~g} / \mathrm{L}$. The reservoir is assumed to be watersaturated before the injection of $\mathrm{CO}_{2}$ and hot water production. The top boundary is set as having no heat or mass flow with an average annual surface temperature of $12{ }^{\circ} \mathrm{C}$.
The bottom boundary is assumed to have no heat or mass flow (BB1), and the lateral boundaries are set as open with heat and mass flows.

\subsubsection{Injection, production, and reinjection strategies}

In the base case, considering the feasibility of the injectivity and engineering operation, the injection pressure and temperature at the well bottom are $30 \mathrm{MPa}$ (approximately 5.2 $\mathrm{MPa}$ higher than the initial reservoir pore pressure) and $10{ }^{\circ} \mathrm{C}$, respectively. In engineering operations, $\mathrm{CO}_{2}$ is often transported by a tank truck or pipeline after compression and cooled to as low as $-20^{\circ} \mathrm{C}$. A booster pump and an electric heater are often employed on the ground at the injection location to increase the pressure and temperature (e.g., to approximately $0{ }^{\circ} \mathrm{C}$ ) for the $\mathrm{CO}_{2}$ injection. Thus, $10{ }^{\circ} \mathrm{C}$ in the base case is a very conservative estimation of the $\mathrm{CO}_{2}$ temperature at the well bottom. Much higher $\mathrm{CO}_{2}$ injection temperatures at the well bottom may be possible when the $\mathrm{CO}_{2}$ temperature is increased at the surface before injection. Thus, different injection temperatures are studied in the sensitivity analysis. The hot water production rate and cooled geothermal return water reinjection rate are set as $2 \mathrm{~kg} / \mathrm{s}$, which is comparable to the average geothermal production rate in Binhai district, while the enthalpy of the reinjection water is assumed to be $42 \mathrm{~kJ} / \mathrm{kg}$ in the base case.

\section{Results}

\subsection{Propagation of pressure and $\mathrm{CO}_{2}$ plume}

When $\mathrm{CO}_{2}$ is injected into aquifers to maintain the reservoir pressure, which is helpful for the production of hot water, the propagation of the pressure plume mainly concentrates at the periphery of the injection well [21]. The affected region is greatly controlled by the lateral migration of $\mathrm{CO}_{2}$ and increases over time (Figs. 6 and 7). At the top of aquifer 2 , the pressure buildup substantially increases with the upward migration of the injected $\mathrm{CO}_{2}$. In addition to the aquifers holding the injected $\mathrm{CO}_{2}$, the pore pressure in the overlying impermeable caprock also substantially increases. At the production well, the pressure at the well 
Table 3. Geological formation properties, initial reservoir conditions, and the injection, production and reinjection parameters used in the simulation studies of the base case.

\begin{tabular}{|c|c|c|}
\hline Parameters & Aquifer & Aquitard \\
\hline \multicolumn{3}{|l|}{ Geological formation } \\
\hline Porosity $(-)$ & 0.3 & 0.1 \\
\hline Permeability $(\mathrm{mD})$ & 50 & 0.001 \\
\hline Pore compressibility $\left(\mathrm{Pa}^{-1}\right)$ & $4.5 \times 10^{-10}$ & $4.5 \times 10^{-10}$ \\
\hline Thickness (m) & 540 & 160 \\
\hline Rock grain density $\left(\mathrm{kg} / \mathrm{m}^{3}\right)$ & 2450 & 2000 \\
\hline Rock grain specific heat $\left(\mathrm{J} / \mathrm{kg}{ }^{\circ} \mathrm{C}\right)$ & 1000 & 1000 \\
\hline Thermal conductivity of the rock formation $\left(\mathrm{W} / \mathrm{m}{ }^{\circ} \mathrm{C}\right)$ & 2.1 & 2.1 \\
\hline \multicolumn{3}{|l|}{ Initial reservoir conditions } \\
\hline Pressure & \multicolumn{2}{|c|}{ Hydrostatic pressure gradient } \\
\hline Temperature gradient $\left({ }^{\circ} \mathrm{C} / 100 \mathrm{~m}\right)$ & \multicolumn{2}{|c|}{2.5} \\
\hline Salinity $(\mathrm{g} / \mathrm{L})$ & \multicolumn{2}{|c|}{1.8} \\
\hline \multicolumn{3}{|l|}{ Boundary conditions } \\
\hline Top boundary & \multicolumn{2}{|c|}{$\begin{array}{l}\text { Average annual surface temperature } \\
12^{\circ} \mathrm{C} \text {, no mass flow }\end{array}$} \\
\hline Bottom boundary & \multicolumn{2}{|c|}{ No mass and heat flow (BB1) } \\
\hline Lateral boundary & \multicolumn{2}{|c|}{ Open with heat and mass flow } \\
\hline \multicolumn{3}{|l|}{ Injection, production and reinjection strategy } \\
\hline Well configuration & \multicolumn{2}{|c|}{$\begin{array}{l}\text { Two production and two water reinjection } \\
\text { wells with another } \mathrm{CO}_{2} \text { injection well } \\
\text { (Type I) }\end{array}$} \\
\hline $\mathrm{CO}_{2}$ injection pressure at the bottom hole $(\mathrm{MPa})$ & \multicolumn{2}{|c|}{30} \\
\hline $\mathrm{CO}_{2}$ injection temperature at the bottom hole $\left({ }^{\circ} \mathrm{C}\right)$ & \multicolumn{2}{|c|}{10} \\
\hline Hot water production rate $(\mathrm{kg} / \mathrm{s})$ & \multicolumn{2}{|c|}{2} \\
\hline Cooled geothermal water reinjection enthalpy $(\mathrm{kJ} / \mathrm{kg})$ & \multicolumn{2}{|c|}{42} \\
\hline Cooled geothermal water reinjection rate $(\mathrm{kg} / \mathrm{s})$ & \multicolumn{2}{|c|}{2} \\
\hline
\end{tabular}

bottom increases over time before the $\mathrm{CO}_{2}$ breakthrough. The pressure sharply decreases when two phases (i.e., $\mathrm{CO}_{2}$ and hot water) are produced for several months. Then, the pressure rebounds to a stable state (Fig. 8).

\subsection{Evolution of $\mathrm{CO}_{2}$ flowing rates and dissolution in the aqueous phase}

In different directions (e.g., downward and outward from the injection point), the difference in the $\mathrm{CO}_{2}$ flow rate increases over time with a maximum difference of $2 \mathrm{~kg} / \mathrm{s}$ after 35 years of geothermal hot water production (Fig. 9). The downward $\mathrm{CO}_{2}$ flow plays a dominant role compared with that in the lateral direction. This result may be driven by gravity effects because the dense water containing dissolved $\mathrm{CO}_{2}$ also strengthens the downward $\mathrm{CO}_{2}$ flow.

The spatial evolution of the $\mathrm{CO}_{2}$ mass fraction in the aqueous phase shows that more $\mathrm{CO}_{2}$ is dissolved into the aqueous phase over time (Fig. 10), which is consistent with the variation trend of the $\mathrm{CO}_{2}$ plume migration. The $\mathrm{CO}_{2}$ dissolved fluid, which has a maximum $\mathrm{CO}_{2}$ mass fraction of $0.05-0.06$ (Fig. 11), migrates to the production well much earlier than the thermal breakthrough (Figs. 10 and 11). In most geothermal reservoirs, the $\mathrm{CO}_{2}$ in the geothermal fluid is enriched; thus, anti-corrosion geothermal pipelines, which can withstand the corrosion induced by fluid with dissolved $\mathrm{CO}_{2}$ for a long period, are applied.

\subsection{Vertical temperature profile along the hot water production well}

The temperature distribution trend along the vertical profile of the hot water production well is shown in Figure 12. After the $\mathrm{CO}_{2}$ breakthrough at the production well, the temperature in sections shallower than $2190 \mathrm{~m}$ increases during the 30-year geothermal production period. At points deeper than the threshold depth (i.e., $2190 \mathrm{~m}$ ), three stages of temperature changes occur. Stage 1 is characterized by a sharp temperature decrease in depth between $-2190 \mathrm{~m}$ and $-2330 \mathrm{~m}$, stage 2 is characterized by a general temperature decrease to a stable state in depths ranging from $-2330 \mathrm{~m}$ to $-2430 \mathrm{~m}$, and a sharp increase in temperature occurs in stage 3 at the bottom layer of the reservoir. Figure 13 shows that the temperature of the production fluid slightly 

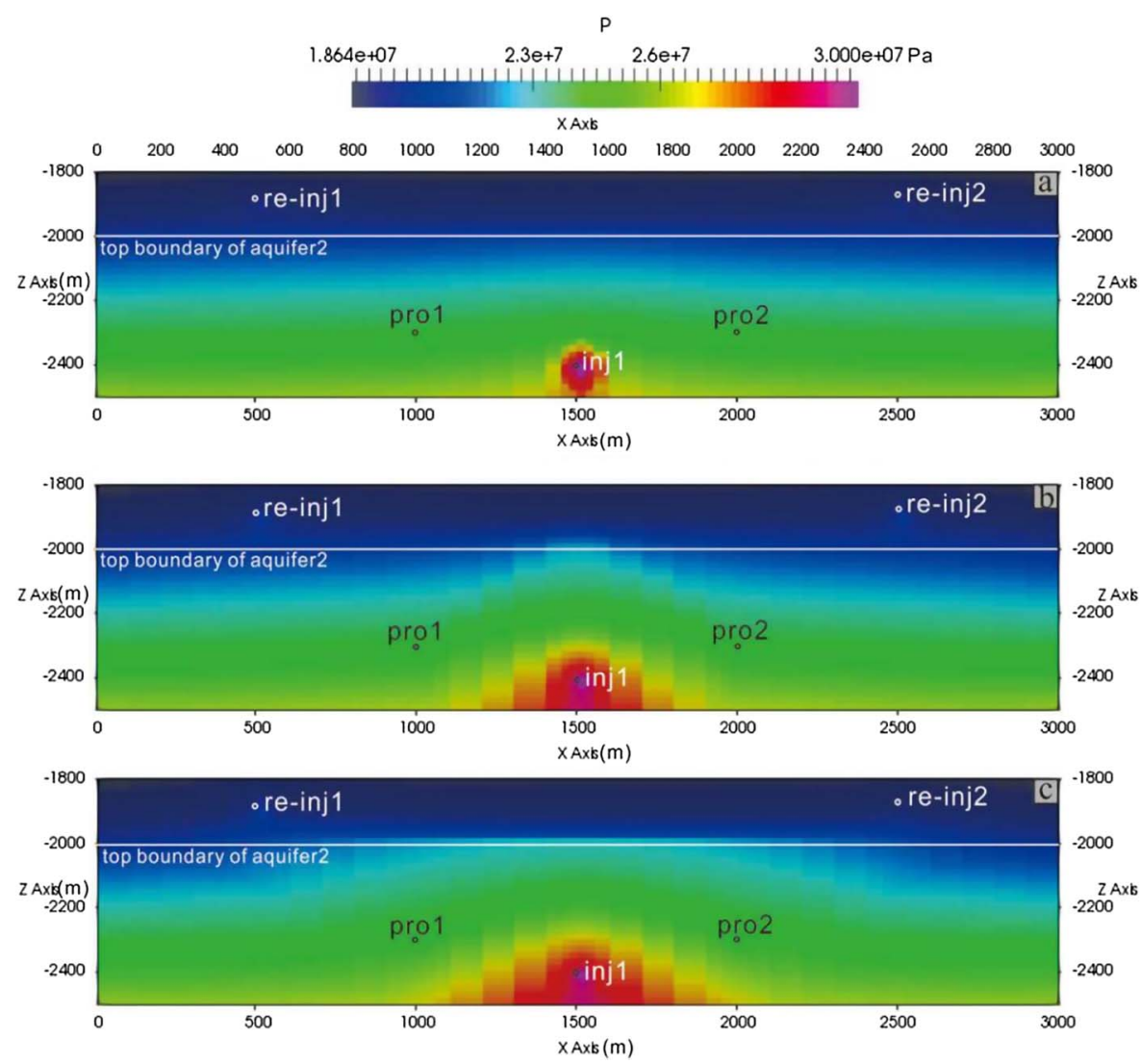

Fig. 6. Propagation of the pore pressure plume over time ((a) 0.1 year, (b) 5 years, and (c) 35 years) during the injection of $\mathrm{CO}_{2}$ and production of hot water in the base case.

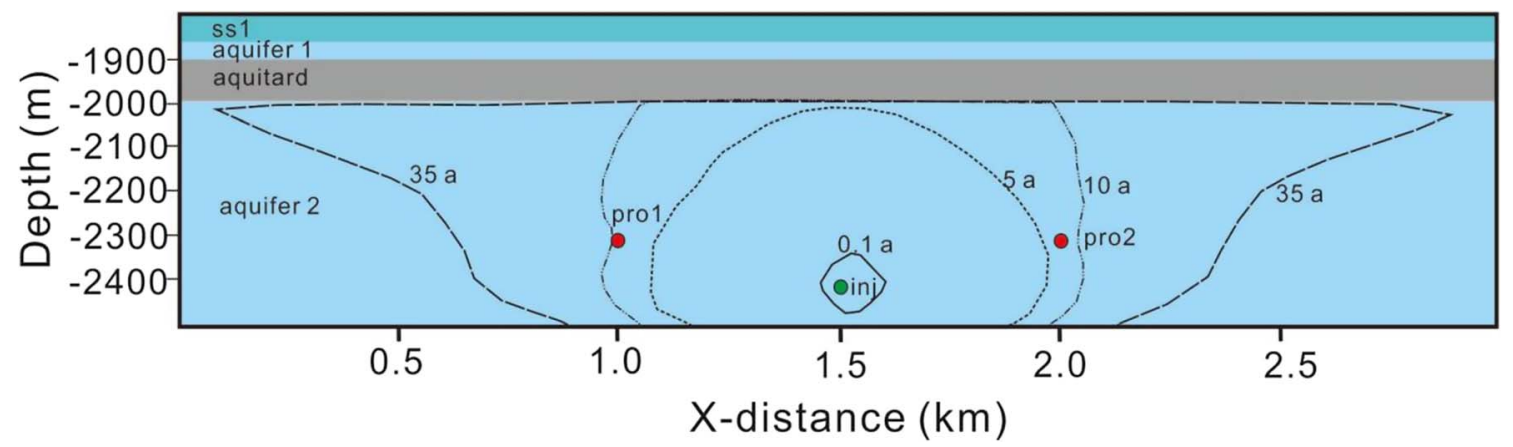

Fig. 7. Spatial migration of the $\mathrm{CO}_{2}$ front over time (0.1 year, 5 years, 10 years, and 35 years shown in different lines) during the injection of $\mathrm{CO}_{2}$ and production of hot water in the base case.

increases after 5 years until the end of 10 years, which is caused by the $\mathrm{CO}_{2}$ breakthrough, and the flowing enthalpy increases accordingly when both $\mathrm{CO}_{2}$ and hot water are extracted at the production well.

\section{Discussion}

To better understand the cooling effects on geothermal reservoirs induced by both the injection of cold $\mathrm{CO}_{2}$ and cooled geothermal return water over the long term and understand the temperature recovery attributable to the heating of neighboring non-affected rock, several scenarios are simulated (see details in Tab. 4) while considering various parameters, including the well configuration (base case, case 1 , and case 2 ), $\mathrm{CO}_{2}$ injection temperature (case 2 vs. cases 3 , and 4 ), $\mathrm{CO}_{2}$ injection-caused reservoir pressure and temperature responses (case 4 vs. case 5), production rate of hot water (case 5 vs. case 6 ), injection pressure and temperature of $\mathrm{CO}_{2}$ (case 2 vs. case 7 ), bottom boundary condition (base case vs. base case 2), and thermal conductivity of the saturated aquifer (case 6 vs. case 8 ). 


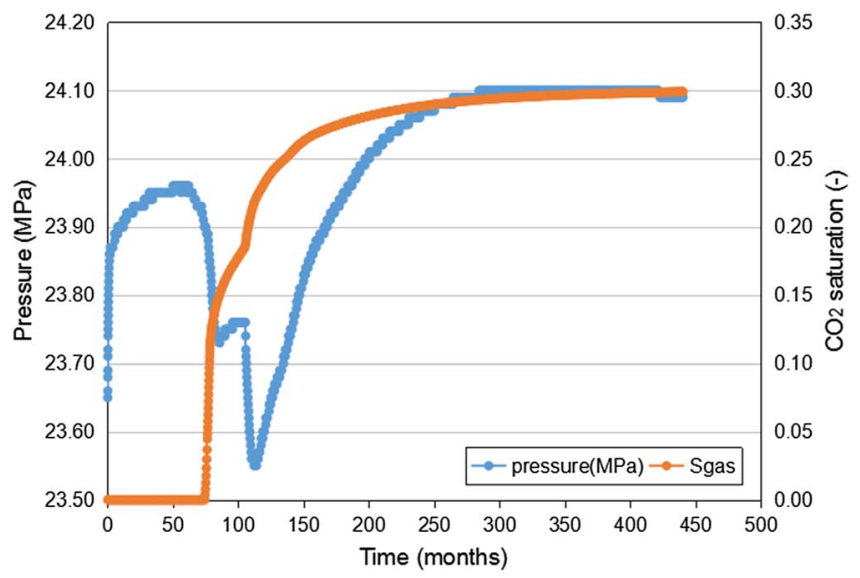

Fig. 8. Pressure and gas saturation changes over time at the production well (base case).

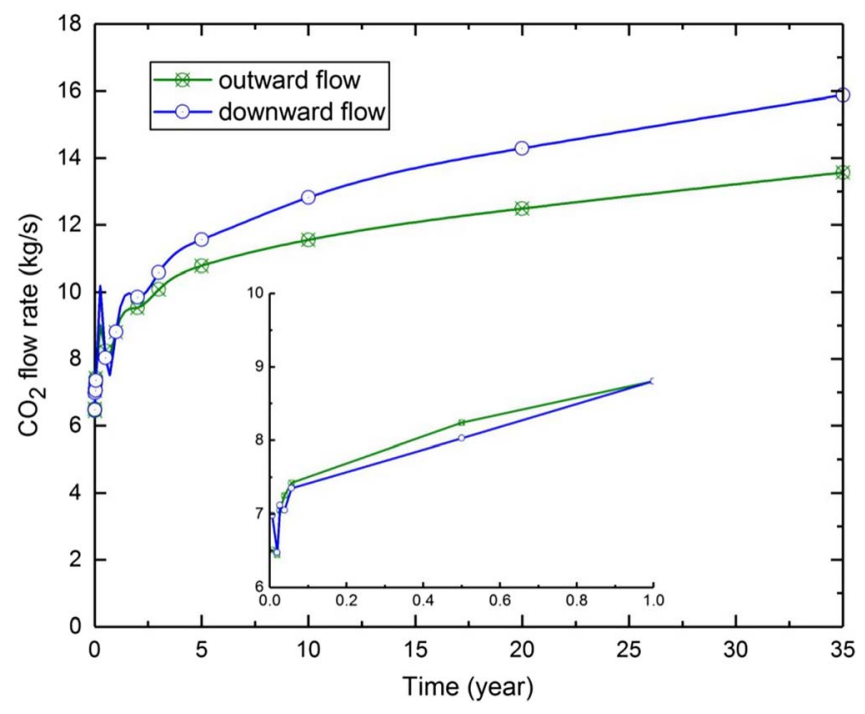

Fig. 9. $\mathrm{CO}_{2}$ flow rates in two directions (outward and downward) at the bottom of the injection well at a depth of $-2410 \mathrm{~m}$ in the base case.

The designs of the scenarios are developed based on many related studies [40-43]. Sensitivity studies are applied to provide an optimized injection-production-reinjection strategy for use in hydrothermal reservoirs. The well configurations in the different scenarios are shown in Figure 14. The simulations in these case studies last for 50 years with continuous injection of $\mathrm{CO}_{2} /$ cooled geothermal water reinjection.

\subsection{Cooling effect in a geothermal reservoir with low injection and extraction rates}

\subsubsection{Temperature changes with and without $\mathrm{CO}_{2}$ injection}

Compared with the traditional geothermal reservoir strategy (i.e., only cooled geothermal water injection), $\mathrm{CO}_{2}$ injection into a geothermal reservoir can increase the reservoir pressure and decrease the $\mathrm{CO}_{2}$ emission into the atmosphere; thus, this approach may be regarded as a more attractive method. The simulation results show that after 10 years of geothermal production, the reservoir temperature surrounding the production wells increases by $2-3{ }^{\circ} \mathrm{C}$ with $\mathrm{CO}_{2}$ injection compared with that under the traditional water injection condition (Fig. 15), although $\mathrm{CO}_{2}$ breakthrough is found at the production well. However, this positive impact on the reservoir temperature only lasts for several years, and a negative effect on the reservoir temperature dominates in the long term. This phenomenon is also supported by numerical studies conducted by other researchers [44].

However, reasonable well configurations and injectionproduction strategies may be helpful for prolonging geothermal production by controlling the negative impacts of thermal breakthrough at the production well. Under low production and reinjection rates of geothermal water (i.e., $2 \mathrm{~kg} / \mathrm{s}$ ), $\mathrm{CO}_{2}$ injection is the main source of thermal breakthrough at the production well over the 50 years of operation. Under the well configuration of type III, different reinjection enthalpies (see cases 2-4) of the cooled geothermal water do not result in differences in the temperature at the production well, indicating that no thermal breakthrough is caused by cooled water reinjection.

\subsubsection{Location of water reinjection wells and the cooling effect of the geothermal reservoir}

The thermal breakthrough at the production well can be controlled by the configuration of the water reinjection wells, which is the most important issue in the design of a traditional water reinjection system [41, 42]. In the geothermal field, water reinjection wells can be located between production wells or far from production wells in the outfield region [43]. Generally, to maintain stable reservoir pressure, cooled geothermal water is often injected into the same formation of low-medium enthalpy geothermal reservoirs. However, serious thermal and chemical breakthrough render the location of reinjection wells at a different layer far from the production formation appealing [37]. In this paper, when the $\mathrm{CO}_{2}$ injection mainly controls the thermal breakthrough, although the water reinjection wells are located at the upper aquifer, which is separated from the production aquifer by a low impermeable caprock, their impact on the thermal breakthrough is negligible (Fig. 16a) compared with the case of water reinjection in the same layer of geothermal reservoirs (Fig. 16c). In contrast, when the $\mathrm{CO}_{2}$ injection wells are completed at the upper parts of the geothermal reservoirs, thermal breakthrough occurs much earlier because more $\mathrm{CO}_{2}$ is injected into the geothermal reservoir under the same injection pressure and temperature conditions (Fig. 16b).

After 20 years of $\mathrm{CO}_{2}$ injection and cooled water reinjection, the small pressure buildup induced by $\mathrm{CO}_{2}$ injection at the same layer pushes the hot water and $\mathrm{CO}_{2}$ flow towards the production well, and the fluid temperature at the production well is significantly decreased (Fig. 17). The upper configuration of the $\mathrm{CO}_{2}$ injection well is helpful for the production of fluid at the lower part of the geothermal 

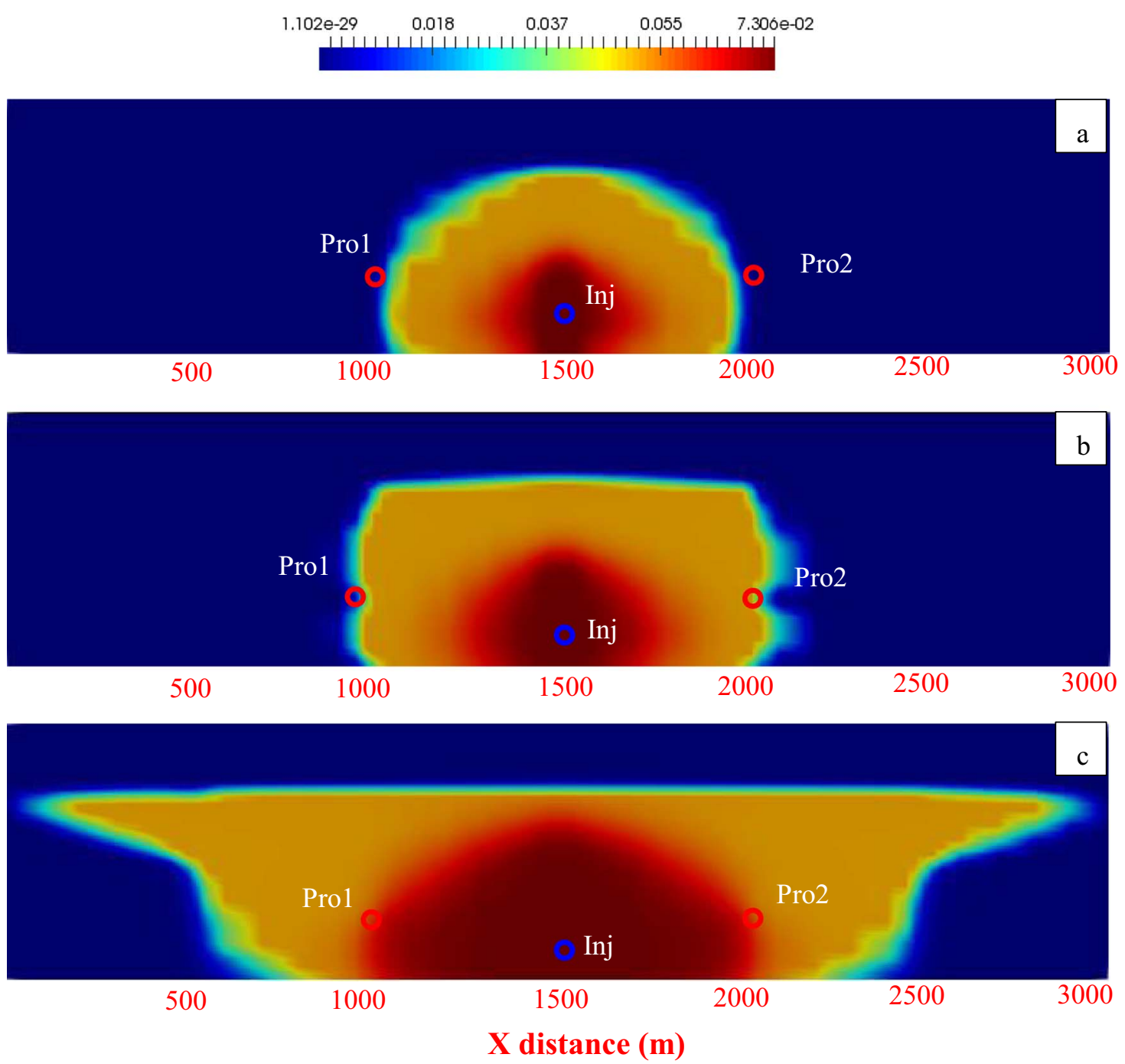

Fig. 10. Spatial distribution of the $\mathrm{CO}_{2}$ mass fraction in the aqueous phase after (a) 5 years, (b) 10 years and (c) 35 years of $\mathrm{CO} 2$ injection.

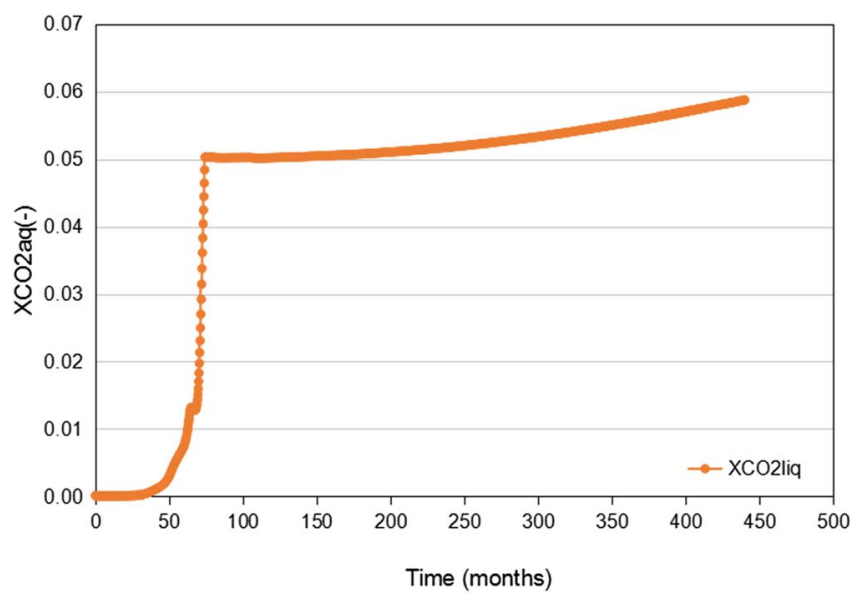

Fig. 11. $\mathrm{CO}_{2}$ mass fraction in the aqueous phase at the bottom of the production well. reservoir, producing a $4{ }^{\circ} \mathrm{C}$ temperature difference compared with that of the lower configuration of the $\mathrm{CO}_{2}$ injection well. There is no temperature difference at the production well among case 2, case 3 , and case 4 based on the numerical simulations; thus, these cases are not listed here.

\subsection{3 $\mathrm{CO}_{2}$ injection state and temperature evolution}

When the injection pressure is set as $30 \mathrm{MPa}$, the annual $\mathrm{CO}_{2}$ storage amount is larger than 2 million tons, and the lateral flowing rate of $\mathrm{CO}_{2}$ increases over time from $7 \mathrm{~kg} / \mathrm{s}$ to $13 \mathrm{~kg} / \mathrm{s}$. The lateral flowing rate of $\mathrm{CO}_{2}$ highly depends on the injection pressure and increases over time [44]. When the injection pressure is decreased to 25.8 $\mathrm{MPa}$ (base case 1), i.e., 4.2 $\mathrm{MPa}$ less than that in the base case, the lateral migration rate of $\mathrm{CO}_{2}$ in the reservoir obviously declines. Under this injection condition, 


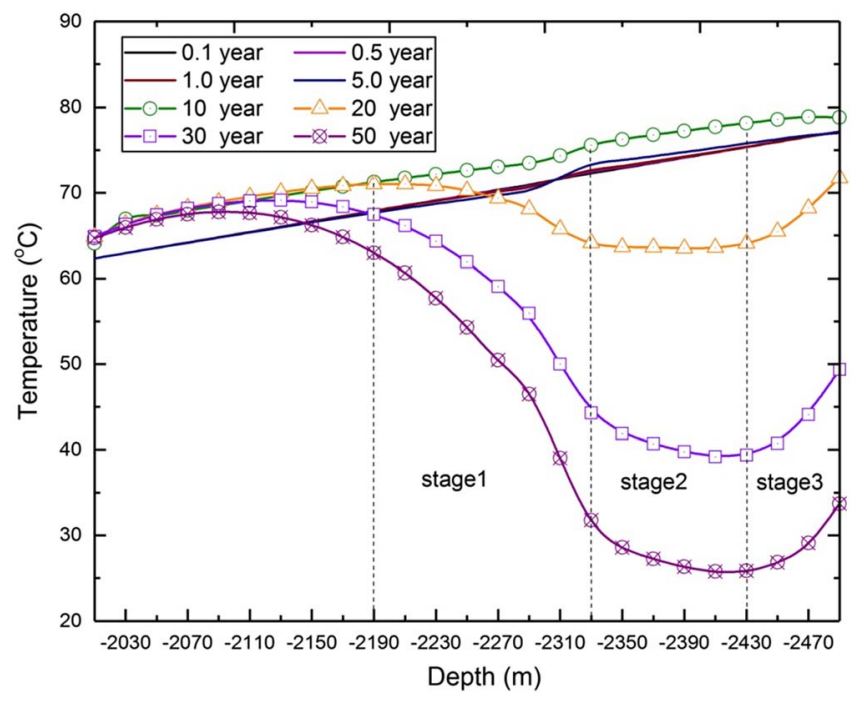

Fig. 12. Temperature changes along the vertical profile of the production well at different times with the reinjection well located at the upper aquifer and separated by an impermeable formation from the hot water production layer in the base case.

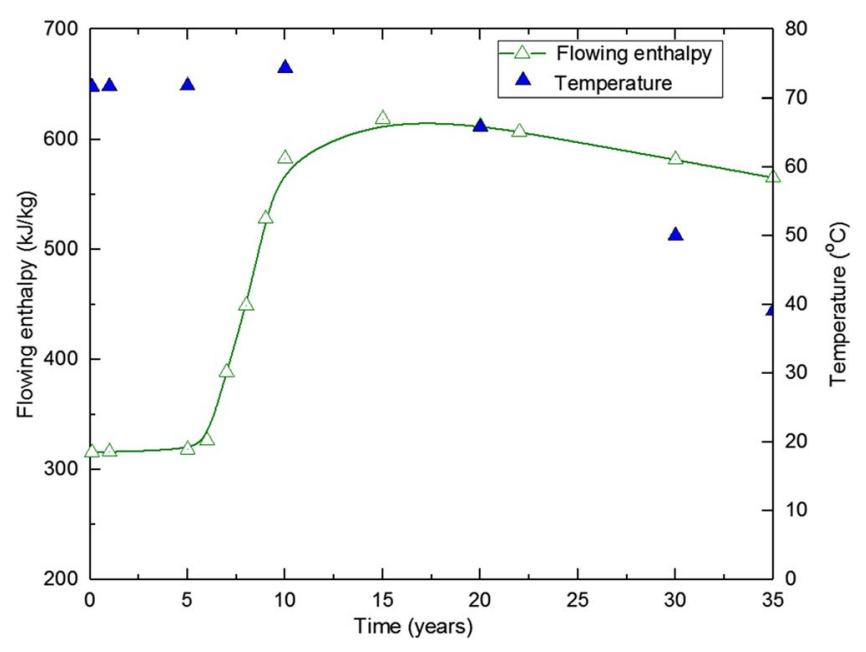

Fig. 13. Flowing enthalpy and temperature changes over time at the production well in the base case.

the annual storage amount of $\mathrm{CO}_{2}$ is approximately 0.4 million tons. The $\mathrm{CO}_{2}$ flow rate in the lateral direction is $4-10 \mathrm{~kg} / \mathrm{s}$ less than that in the base case (Fig. 18). The minor difference in injection pressure (i.e., $0.2 \mathrm{MPa}$ ) between base case 1 and case 7 results in an obvious difference in the $\mathrm{CO}_{2}$ flow rate of $1 \mathrm{~kg} / \mathrm{s}$. When $\mathrm{CO}_{2}$ is injected at the well bottom located at the upper part of the aquifer (cases 1-1), a much larger $\mathrm{CO}_{2}$ flowing rate (i.e., by more than two times) than that in case 7 occurs under the same injection pressure and temperature conditions (i.e., $26 \mathrm{MPa}$ and $25^{\circ} \mathrm{C}$ ).

By comparing the temperature changes in the extracted geothermal fluid at the production wells under different production strategies, it can be observed that a decreased injection pressure (see base case 1 and case 7 ) can greatly inhibit the cooling effect surrounding the production wells (Fig. 19). This inhibition is due to the late $\mathrm{CO}_{2}$ breakthrough and cooled geothermal water at the production well. The $\mathrm{CO}_{2}$ breakthrough occurs much earlier than the thermal breakthrough under high $\mathrm{CO}_{2}$ injection rates, and the flowing temperature at the production well increases over the 12 years of production. Under the same injection pressure, when the $\mathrm{CO}_{2}$ injection well is located at the upper part of the reservoir, colder $\mathrm{CO}_{2}$ is injected, which is unfavorable compared to the geothermal production caused by much earlier thermal breakthrough. However, when the injection pressure decreases and the distance between production wells increases, the thermal breakthrough is greatly inhibited, and the reservoir temperature declines by less than $5{ }^{\circ} \mathrm{C}$ even though much more $\mathrm{CO}_{2}$ is injected compared with that in case 7 . Under low reinjection rates $(2 \mathrm{~kg} / \mathrm{s})$, the cooled geothermal water reinjected at the same layer does not reach the production well. Thus, a similar variation trend of the fluid temperature at the production well occurs in the base case and case 2 .

\subsubsection{Impact of the bottom boundary on the geothermal field}

When a constant heat flux (i.e., $54 \mathrm{~mW} / \mathrm{m}^{2}$ ) is set at the bottom boundary of the geothermal reservoir, the production fluid temperature only shows minor changes (Fig. 20), indicating that its contribution to the temperature field is negligible.

\subsection{Cooling effect on the geothermal reservoir by commercial-scale hot water extraction and reinjection}

\subsubsection{Pressure response}

In most geothermal fields, the reinjected mass includes geothermal waste fluid (i.e., brine and condensates) and additional water, such as river water [45], treated waste water [46], and supplementary water [47]. $\mathrm{CO}_{2}$ is not injected into geothermal reservoirs with a low proportion of $\mathrm{CO}_{2}$ production. When the production rate is increased to a commercial scale $\left(100 \mathrm{~m}^{3} / \mathrm{h}\right)$, the reservoir pressure buildup at the reinjection wells and pressure decrease at the production wells are very obvious (Fig. 21). The pressure response to the injection of cooled return water is rapid, which has been proven by many injection tests, including that at Well HE-04 of Reykjanes in Iceland with a pore pressure increase of $0.1 \mathrm{MPa}$ after $2 \mathrm{~h}$ of water injection and an injection rate increase of $50 \%$ [48]. A water level increase also occurred in an Otake geothermal field within a short period after water reinjection into the reservoir [49]. The water level will obviously increase in Tianjin due to the commercial-scale reinjection of cold water [50].

\subsubsection{Temperature changes in the geothermal reservoir}

Because of the reinjection of cooled geothermal return water, the reservoir is substantially cooled at the regions 
Table 4. Conditions and parameters used in different scenarios for the sensitivity analysis.

\begin{tabular}{|c|c|c|c|c|c|c|c|c|c|c|c|c|}
\hline & $\begin{array}{c}\text { Base } \\
\text { case } 1\end{array}$ & $\begin{array}{c}\text { Base } \\
\text { case } 2 \\
\end{array}$ & Case 1 & $\begin{array}{c}\text { Cases } \\
1-1 \\
\end{array}$ & $\begin{array}{c}\text { Cases } \\
1-2 \\
\end{array}$ & Case 2 & Case 3 & Case 4 & Case 5 & Case 6 & Case 7 & Case 8 \\
\hline $\begin{array}{l}\mathrm{CO}_{2} \text { injection pressure } \\
\text { at the bottom hole } \\
(\mathrm{MPa})\end{array}$ & 25.8 & 30 & 30 & 26 & 26 & 30 & 30 & 30 & - & - & 26 & - \\
\hline $\begin{array}{l}\mathrm{CO}_{2} \text { injection } \\
\text { temperature at the } \\
\text { bottom hole }\left({ }^{\circ} \mathrm{C}\right)\end{array}$ & 10 & 10 & 10 & 25 & 25 & 10 & 10 & 10 & - & - & 25 & - \\
\hline $\begin{array}{l}\text { Water prod flow rate at } \\
\operatorname{pro} 1(\mathrm{~kg} / \mathrm{s})\end{array}$ & 2 & 2 & 2 & 2 & 2 & 2 & 2 & 2 & 2 & 27.8 & 2 & 27.8 \\
\hline $\begin{array}{l}\text { Water prod rate at pro } 2 \\
(\mathrm{~kg} / \mathrm{s})\end{array}$ & 2 & 2 & 2 & 2 & 2 & 2 & 2 & 2 & 2 & 27.8 & 2 & 27.8 \\
\hline $\begin{array}{l}\text { Tail water reinjection } \\
\text { rate }(\mathrm{kg} / \mathrm{s})\end{array}$ & 2 & 2 & 2 & 2 & 2 & 2 & 2 & 2 & 2 & 27.8 & 2 & 27.8 \\
\hline $\begin{array}{l}\text { Tail water reinjection } \\
\text { flow rate at re-inj2 } \\
(\mathrm{kg} / \mathrm{s})\end{array}$ & $<2$ & $<2$ & $<2$ & $<2$ & $<2$ & $<2$ & $<2$ & $<2$ & $<2$ & $<27.8$ & $<2$ & $<27.8$ \\
\hline $\begin{array}{l}\text { Tail water reinjection } \\
\text { enthalpy at re-inj1 } \\
(\mathrm{kJ} / \mathrm{kg})\end{array}$ & 42 & 42 & 42 & 42 & 42 & 42 & 83.96 & 125.75 & 125.75 & 125.75 & 42 & 125.75 \\
\hline $\begin{array}{l}\text { Tail water reinjection } \\
\text { enthalpy at re-inj2 } \\
(\mathrm{kJ} / \mathrm{kg})\end{array}$ & 42 & 42 & 42 & 42 & 42 & 42 & 83.96 & 125.75 & 125.75 & 125.75 & 42 & 125.75 \\
\hline $\begin{array}{l}\text { Thermal conductivity } \\
\text { of aquifers } \\
\left(\mathrm{W} /\left(\mathrm{m}{ }^{\circ} \mathrm{C}\right)\right)\end{array}$ & 2.1 & 2.1 & 2.1 & 2.1 & 2.1 & 2.1 & 2.1 & 2.1 & 2.1 & 2.1 & 2.1 & 3.5 \\
\hline Well configuration & Type I & Type I & Type II & Type II & Type II & Type III & Type III & Type III & Type IV & Type IV & Type III & Type IV \\
\hline Bottom boundary & BB1 & BB2 & BB1 & BB1 & BB1 & BB1 & BB1 & BB1 & BB1 & BB1 & BB1 & BB1 \\
\hline $\begin{array}{l}\text { Distance between } \\
\text { production wells }(\mathrm{km})\end{array}$ & 1 & 1 & 1 & 1 & 2 & 1 & 1 & 1 & 1 & 1 & 1 & 1 \\
\hline
\end{tabular}

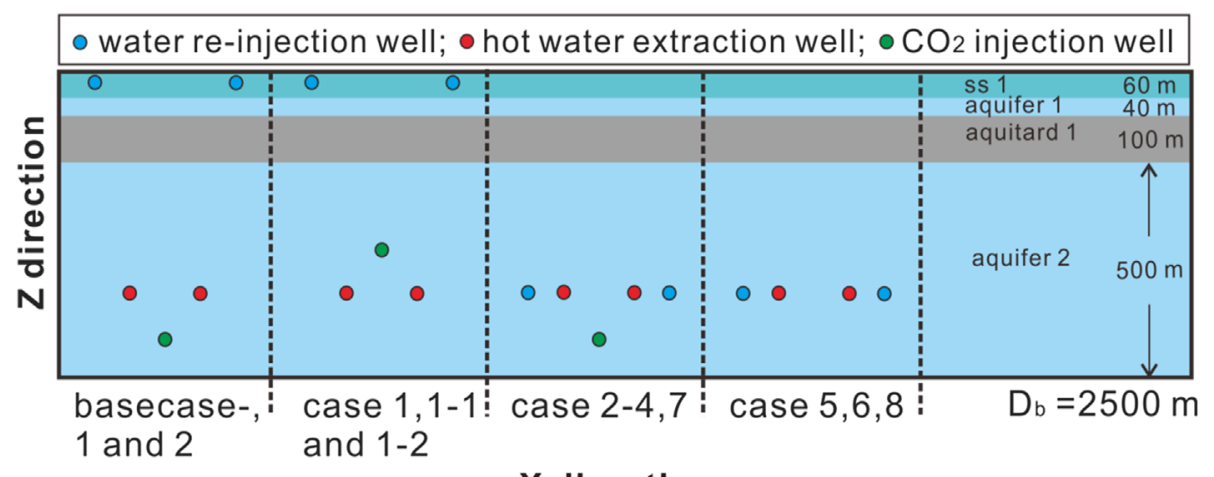

\section{$\mathrm{X}$ direction}

Fig. 14. Schematic diagram of the well configurations (types I, II, III, and IV) in the $X Z$ direction in the different scenarios.

surrounding the reinjection well, and the cold region increases over time (Fig. 22). However, the short-term monitoring results (less than 1 month) imply that there is no decrease in the reservoir temperature at the production well [51] because no thermal breakthrough occurs at the production well within several days. Thermal breakthrough may occur in the production well (500 $\mathrm{m}$ in distance) after a period of production (months or years) depending on 


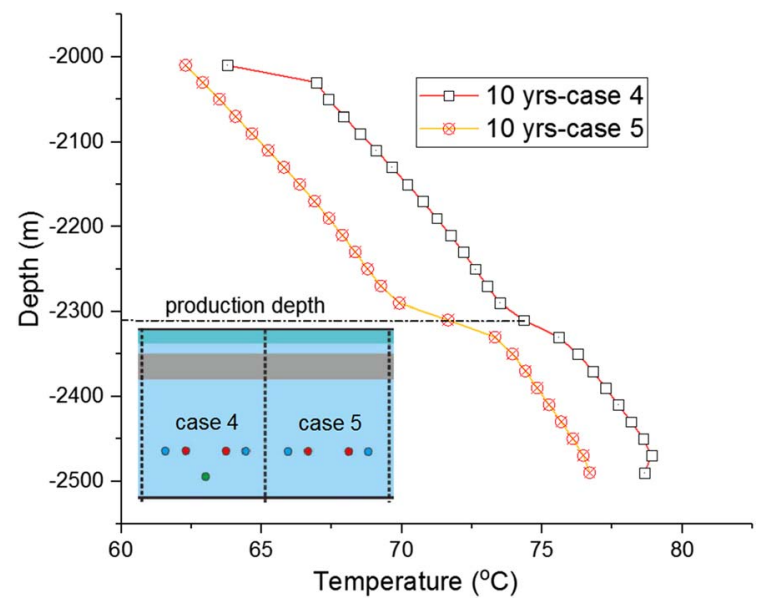

Fig. 15. Comparison of temperature changes along the vertical profile proceeding through the production well block after 10 years of operation with $\mathrm{CO}_{2}$ injection (case 4) and without $\mathrm{CO}_{2}$ injection (case 5). the well configuration and reinjection and production rates. The reinjection of cooled geothermal water in the Xiaotangshan geothermal field in China showed a temperature decrease of $7{ }^{\circ} \mathrm{C}$ in the geothermal reservoir after 10 years of reinjection. Here, in the numerical simulation, after 50 years of geothermal production, the maximum temperature decrease in the reservoir at the production well (pro1) is approximately $20^{\circ} \mathrm{C}$ during the full cooled water reinjection treatment. The vertical temperature profile along the hot water production well is shown in Figure 23.

\subsubsection{Injection rate effects on the temperature evolution}

The comparison between the low and high reinjection rates of cooled geothermal water (case 5 vs. case 6 ) demonstrates that the reservoir temperature is not negatively affected in the short term (less than 5 years). A minor temperature decrease of $2{ }^{\circ} \mathrm{C}$ appears after 10 years, while the maximum temperature difference is approximately $8^{\circ} \mathrm{C}$ after 20 years of water reinjection (Fig. 24).
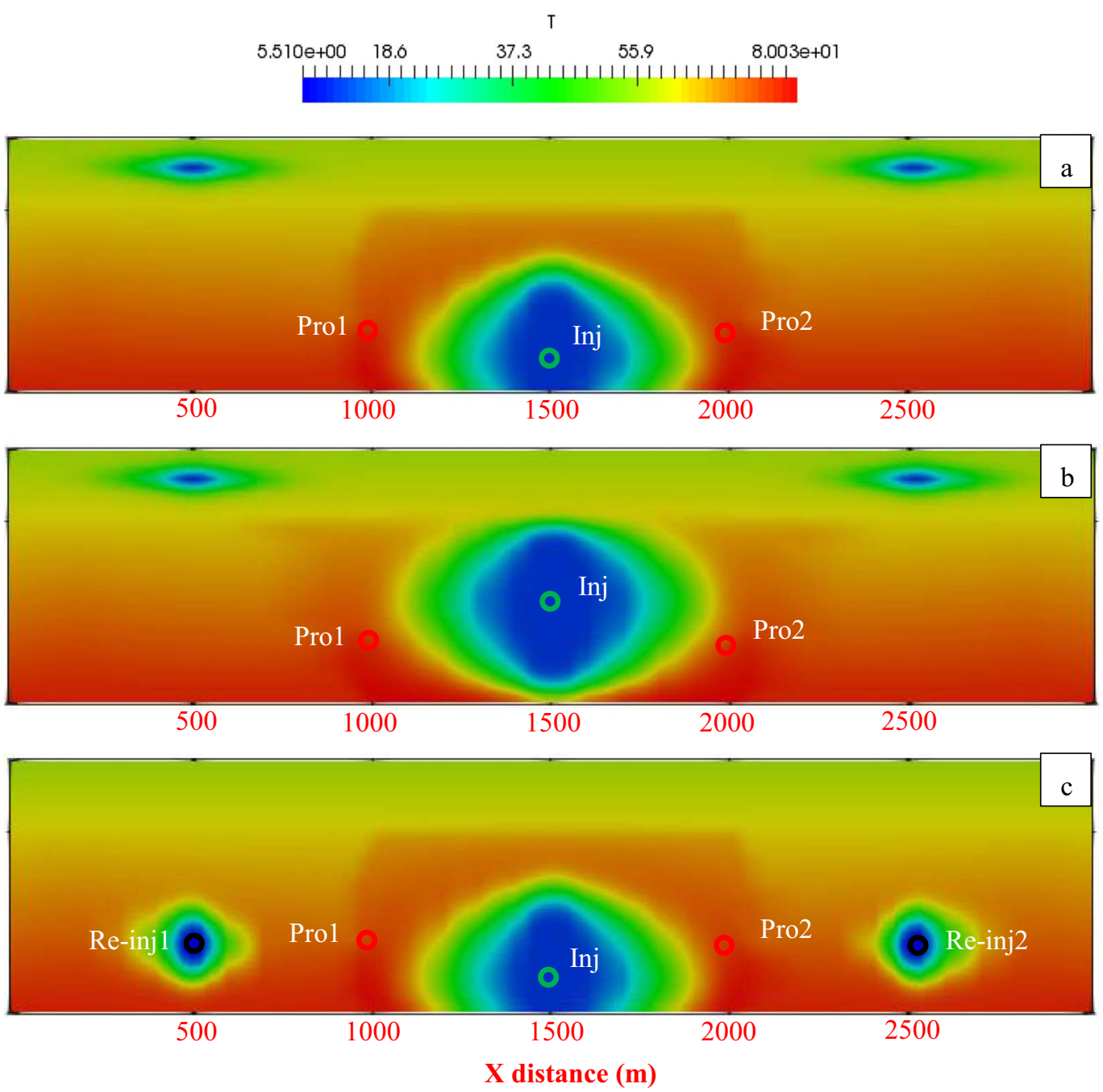

Fig. 16. Comparison of the temperature evolution after 10 years of $\mathrm{CO}_{2}$ injection using different well configurations ((a) base case, (b) case 1 , and (c) case 2). 


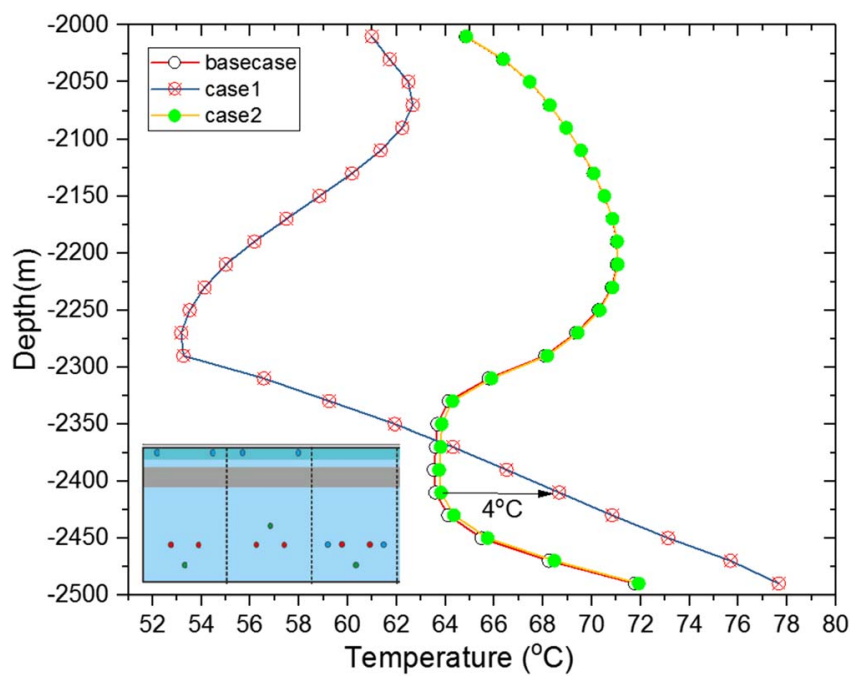

Fig. 17. Temperature changes along the vertical profile of the production well over 20 years with different reinjection locations (base case, case 1 , and case 2).

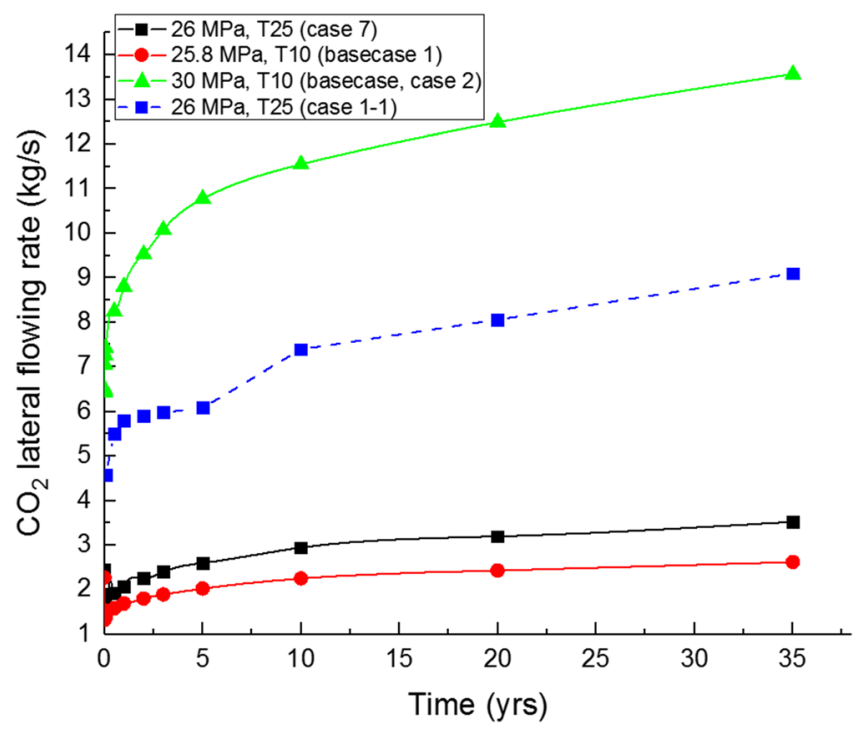

Fig. 18. $\mathrm{CO}_{2}$ outward flow rates under different injection conditions at the injection well block at a depth of $-2410 \mathrm{~m}$.

\subsubsection{Thermal conductivity effect on the temperature evolution}

The increased thermal conductivity in the production aquifer plays a very minor role in the temperature profile along the production well. The simulation shows that less than $1{ }^{\circ} \mathrm{C}$ of a temperature difference occurs after 30 years of geothermal production (Fig. 25). This finding implies that compared with other factors, including the fluid injection and production rates, fluid injection temperature, well configuration, etc., the contribution of thermal conductivity to the temperature is negligible.

Therefore, considering that this information includes reservoir properties, production and injection conditions,

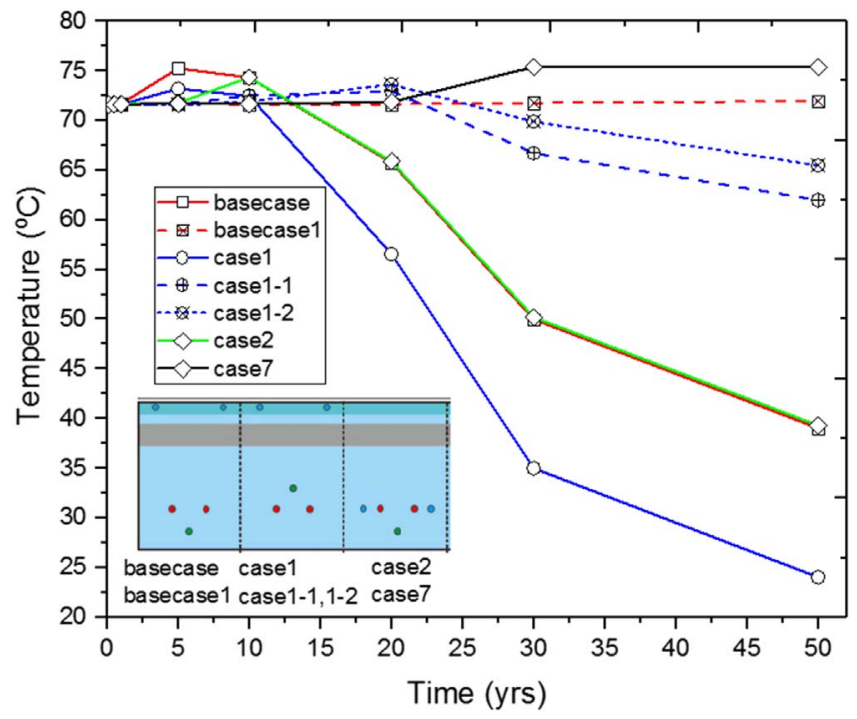

Fig. 19. Temperature changes in the production well induced by $\mathrm{CO}_{2}$ and cooled geothermal water injection under different conditions.

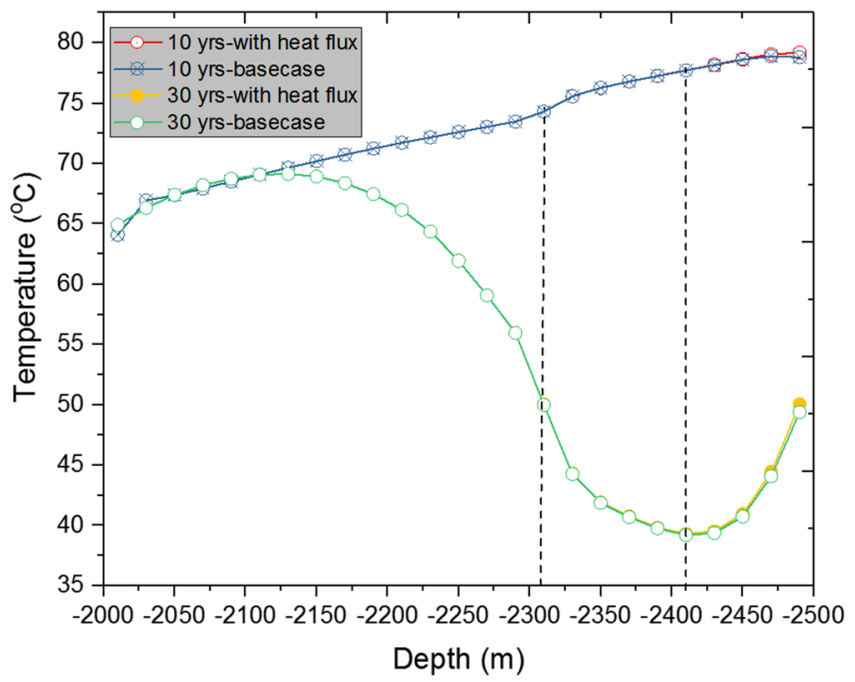

Fig. 20. Variation in the temperature profile along the production well induced by $\mathrm{CO}_{2}$ injection under two different bottom boundary conditions (base case vs. base case 2).

reinjection strategies, and the responses of geothermal reservoirs from past experience with reinjection practices [41], the comprehensive comparison results are listed in the above sections. When the water production and water reinjection rates are low $(2 \mathrm{~kg} / \mathrm{s})$, their impact on the fluid temperature at the production well is negligible, and thermal breakthrough is mainly caused by the injection of cold $\mathrm{CO}_{2}$ (see the results of the base case, base case 1, case 1 , etc.). A comparison of these cases (with and without $\mathrm{CO}_{2}$ injection in case 5 and case 6 ) shows that the temperature decrease is very limited $\left(<0.5{ }^{\circ} \mathrm{C}\right)$ when the production rate is very low $(2 \mathrm{~kg} / \mathrm{s})$ and that the reinjection enthalpy is $125.75 \mathrm{~kJ} / \mathrm{kg}$. However, when the production and 


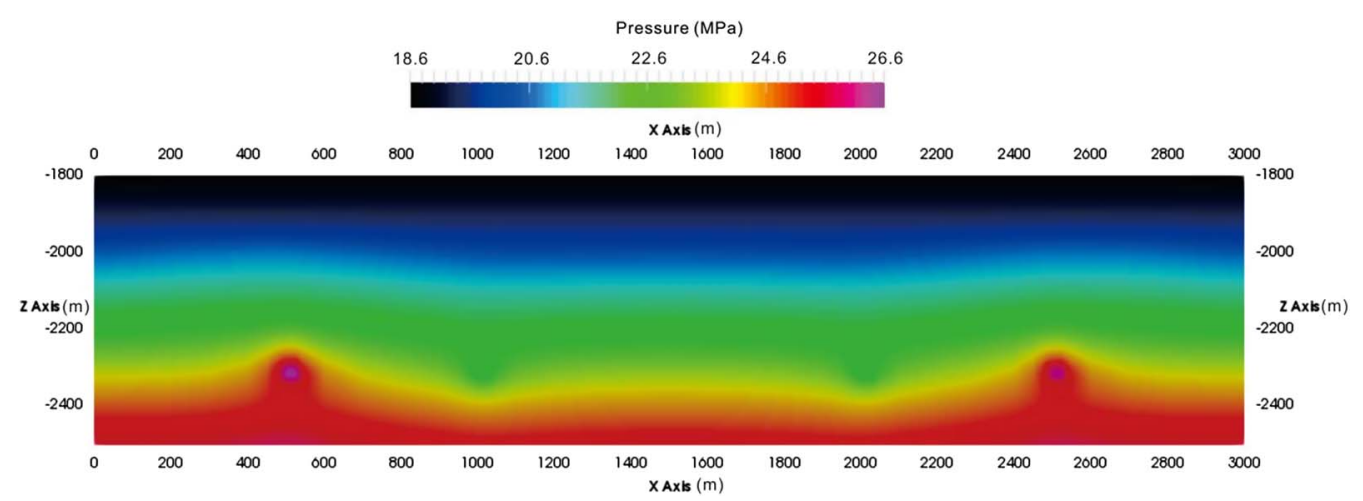

Fig. 21. Spatial distribution of pore pressure induced by commercial-scale hot water extraction $\left(100 \mathrm{~m}^{3} / \mathrm{h}\right)$ and cooled geothermal return water reinjection at the end of 10 years (case 6).

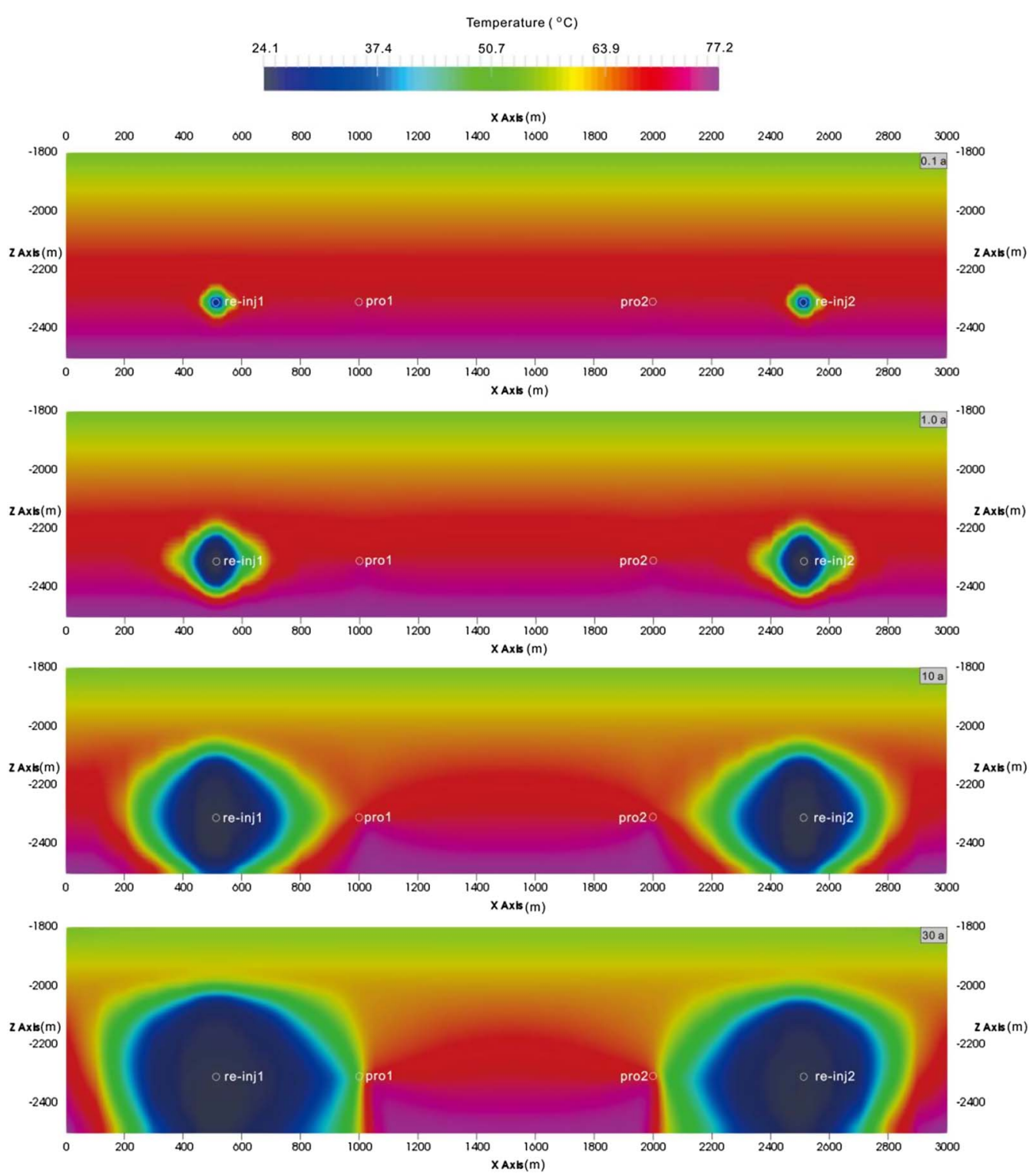

Fig. 22. Spatial distribution of the reservoir temperature induced by hot water extraction $\left(100 \mathrm{~m}^{3} / \mathrm{h}\right)$ and cooled geothermal water reinjection at different times, including 0.1 year, 1.0 year, 10 years, and 30 years (case 6 ). 


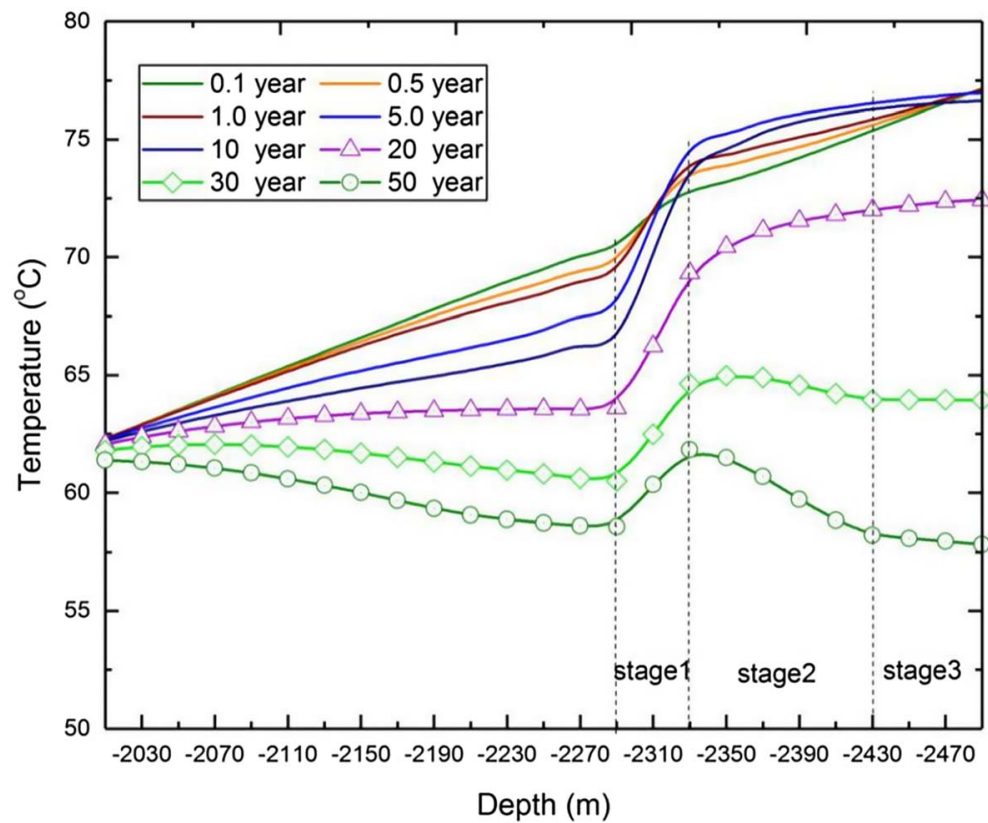

Fig. 23. Temperature changes along the vertical profile of the production well at different times with a production rate of $100 \mathrm{~m}^{3} / \mathrm{h}$ and no $\mathrm{CO}_{2}$ injection (case 6).

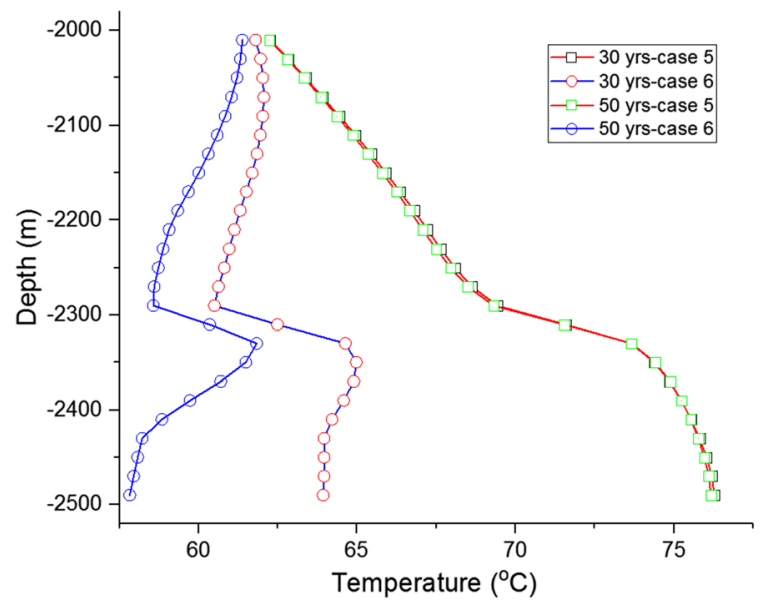

Fig. 24. Comparison of the vertical temperature profile along the production well after 30 and 50 years of water reinjection at two different reinjection rates (i.e., $2 \mathrm{~kg} / \mathrm{s}$ and $27.8 \mathrm{~kg} / \mathrm{s}$ ).

reinjection rates are high $(27.8 \mathrm{~kg} / \mathrm{s})$, even without $\mathrm{CO}_{2}$ reinjection into the reservoir, the thermal breakthrough caused by the water reinjection is very strong. The temperature decrease in the production water reaches $5.4{ }^{\circ} \mathrm{C}, 9.2{ }^{\circ} \mathrm{C}$ and $11.3{ }^{\circ} \mathrm{C}$ after 20,30 , and 50 years of geothermal production, respectively. When the injection temperature of the $\mathrm{CO}_{2}$ increases to $25^{\circ} \mathrm{C}$, the produced fluid temperature increases compared with that in the initial state because of the much higher flowing enthalpy. The impact of the reservoir thermal conductivity on the temperature of the extracted fluid is negligible when the production rate is high.

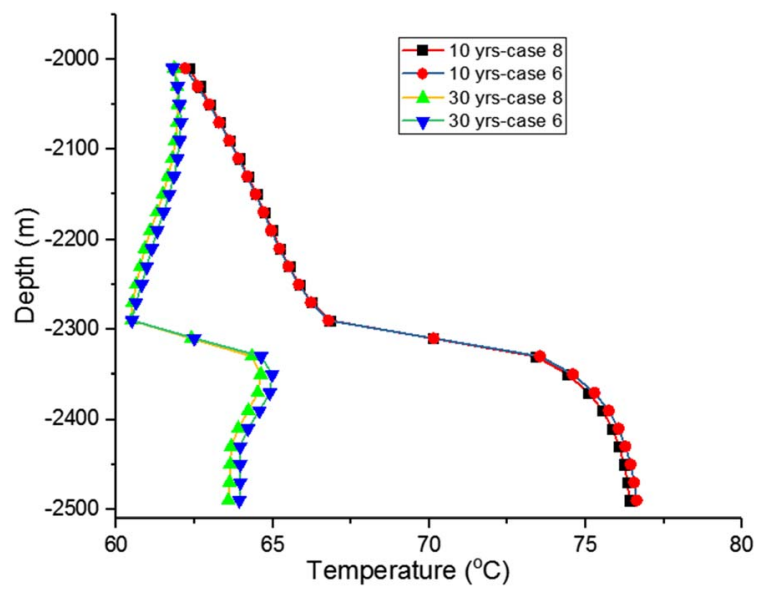

Fig. 25. Comparison of the vertical temperature profile along the production well after 10 and 30 years of geothermal production with two different thermal conductivities.

\subsection{Methods inhibiting early $\mathrm{CO}_{2}$ breakthrough}

From an operational perspective, the main purpose of $\mathrm{CO}_{2}$ injection into the geothermal reservoir is to increase the efficiency of hot water production. Therefore, the $\mathrm{CO}_{2}$ injection pressure can be decreased to inhibit early $\mathrm{CO}_{2}$ breakthrough (e.g., base case 1 and case 7 ) as shown in Figures 26 and 27. Thus, the win-win effect of $\mathrm{CO}_{2}$ injection into the geothermal reservoir can be achieved by enabling the storage of $\mathrm{CO}_{2}$.

If the $\mathrm{CO}_{2}$ injection amount is not decreased, the lateral distance of the production wells can be increased to prolong 


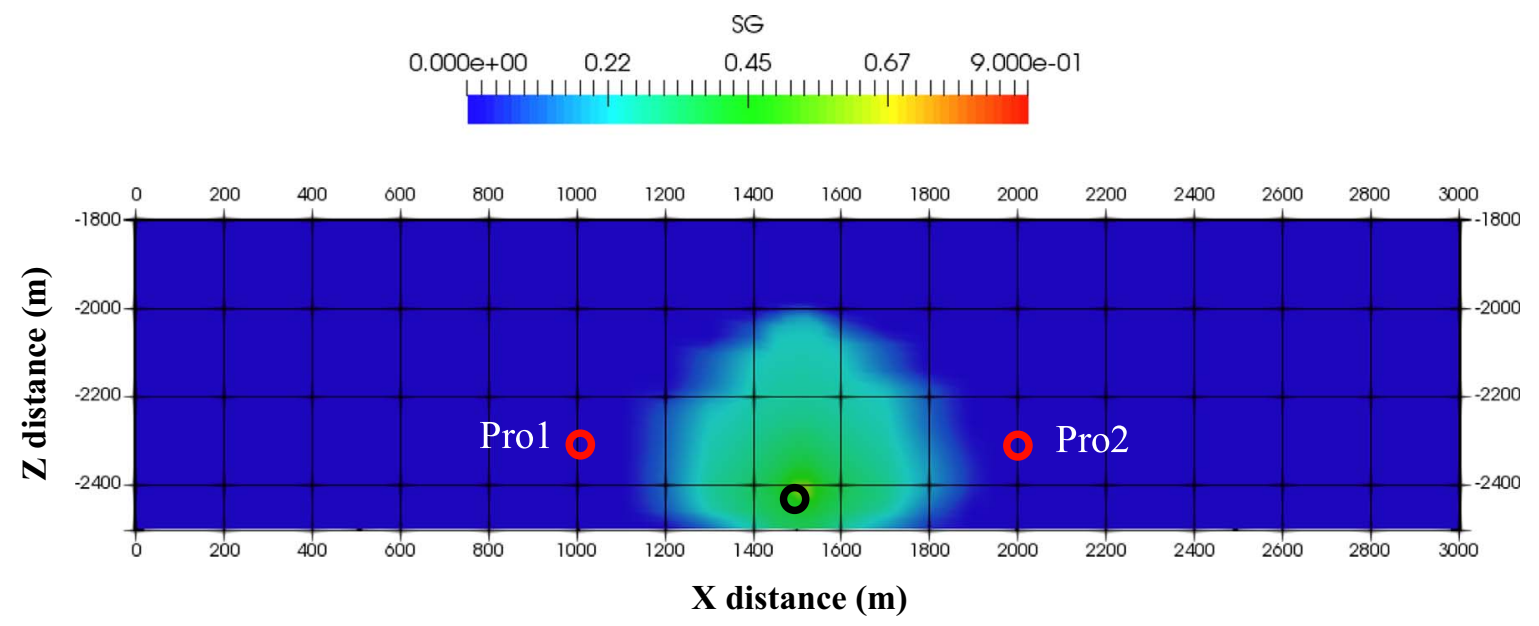

Fig. 26. Spatial distribution of $\mathrm{CO}_{2}$ after 10 years of injection in base case 1.

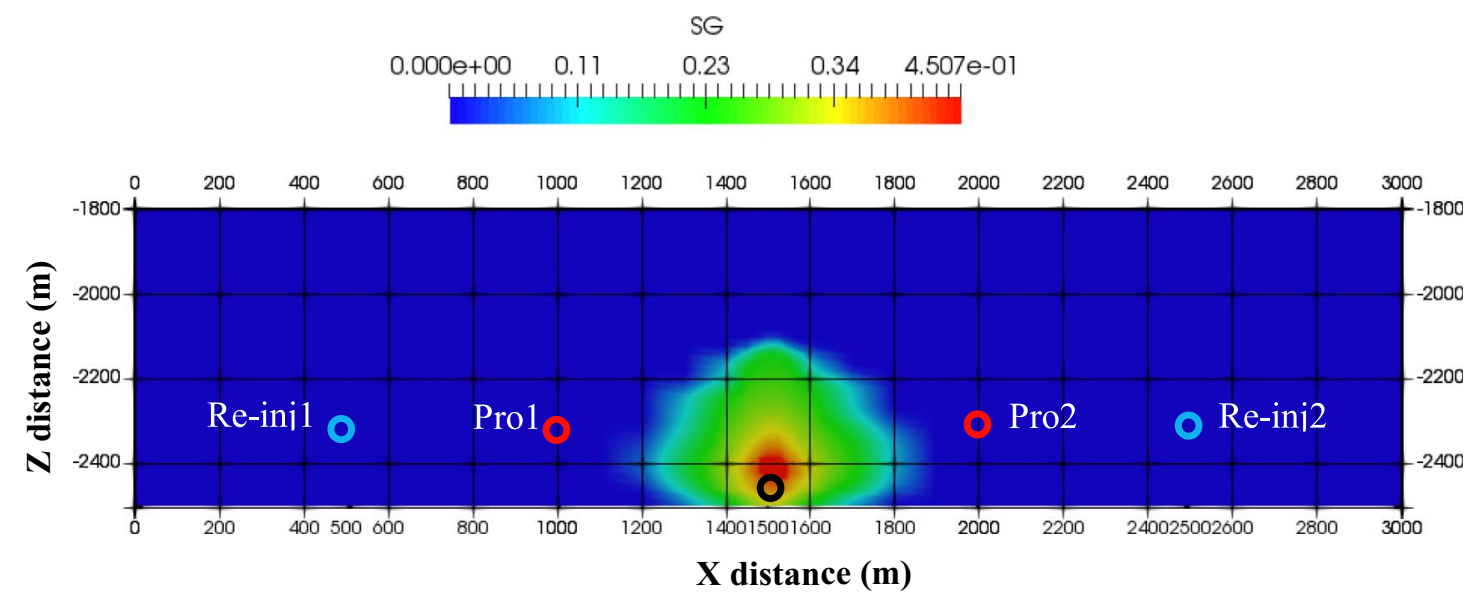

Fig. 27. Spatial distribution of $\mathrm{CO}_{2}$ after 10 years of injection in case 7 .

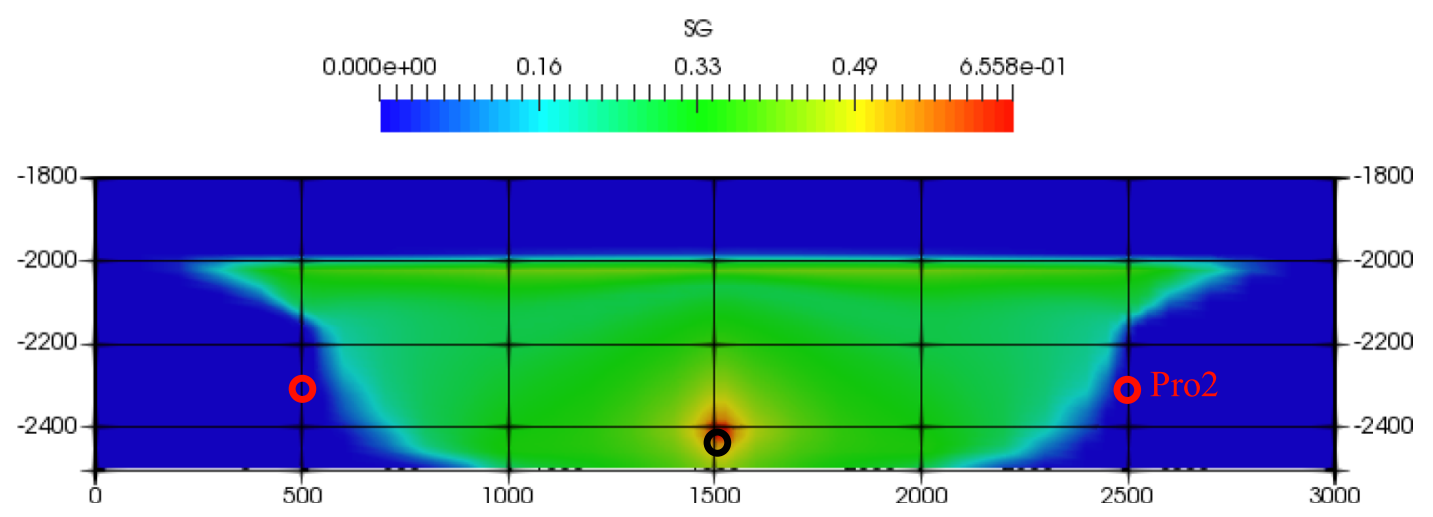

Fig. 28. Spatial distribution of gas saturation after 30 years by increasing the lateral distance between the $\mathrm{CO}_{2}$ injection point and hot water production point to $1 \mathrm{~km}$.

the $\mathrm{CO}_{2}$ breakthrough. We performed a simulation test at a lateral distance of $1 \mathrm{~km}$ between the $\mathrm{CO}_{2}$ injection point and the hot water production point while maintaining the other conditions the same as in the base case. Compared with the base case (Fig. 7), it is found that no $\mathrm{CO}_{2}$ breakthrough occurs after 30 years of $\mathrm{CO}_{2}$ injection when the lateral distance between the $\mathrm{CO}_{2}$ injection point and the hot water production point is increased to $1 \mathrm{~km}$ (Fig. 28). 


\section{Summary and conclusion}

Serious air pollution has accelerated the need to change the energy consumption structure in China, providing a good opportunity for the development of renewable energy, especially deep geothermal energy. Win-win $\mathrm{CO}_{2}$-aided geothermal energy strategies can be applied in low-medium enthalpy hydrothermal reservoirs to simultaneously maintain the pressure balance, inhibit ground subsidence to some extent, and reduce $\mathrm{CO}_{2}$ emissions.

A new mode consisting of a $\mathrm{CO}_{2}$ injection, hot water production, and cooled geothermal return water reinjection system is presented in this paper. Based on numerical studies applying $\mathrm{CO}_{2}$-AGES to the low-medium enthalpy hydrothermal reservoirs of the Guantao formation using the conceptual geological model of a small region in Binhai district in Tianjin, the following main conclusions can be drawn:

1. $\mathrm{CO}_{2}$ injection is feasible for maintaining the reservoir pressure. However, a suitable injection strategy (i.e., injection pressure and temperature, well configuration, etc.) should be applied to prolong hot water production. $\mathrm{CO}_{2}$ breakthrough occurs much earlier than thermal breakthrough, demonstrating that the production temperature increases even after $\mathrm{CO}_{2}$ breakthrough occurs.

2. When the injection pressure decreases from $30 \mathrm{MPa}$ to $26 \mathrm{MPa}$, the $\mathrm{CO}_{2}$ flow rate rapidly decreases, which is beneficial for hot water extraction at the production well (late $\mathrm{CO}_{2}$ breakthrough).

3. Pore pressure buildup occurs in the overlying caprocks, but the $\mathrm{CO}_{2}$ front stops at the bottom of the caprock layer. The pressure front is much larger than the $\mathrm{CO}_{2}$ plume front.

4. After $\mathrm{CO}_{2}$ breakthrough at the production well, during the two phase fluid (i.e., $\mathrm{CO}_{2}+$ water) flow period, the temperature of the extracted fluid increases compared with that under the pure hot water production condition. This phenomenon lasts for several years before a sharp decrease in the fluid temperature at the production well is induced by the production of pure $\mathrm{CO}_{2}$.

5. The thermal breakthrough induced by the reinjection of cooled geothermal water is very limited and caused by a low water reinjection rate.

6. Water production and reinjection rates greatly control the degree of the cooling effect in geothermal reservoirs. The extracted water temperature greatly decreases after long-term geothermal production when the hot water production and cooled water reinjection rates increase from $2 \mathrm{~kg} / \mathrm{s}$ to $27.8 \mathrm{~kg} / \mathrm{s}$.

$\mathrm{CO}_{2}$-aided geothermal extraction technology is only at the early research stage, and more work is required before its commercial application. The cooling effects of a geothermal reservoir characterized by multiple thin layers segmented by complex fault or fracture systems require further investigation. Tracer tests are also required to understand the flow channels of reinjected return water. These issues will be considered in future works.
Acknowledgments. This research was funded by the CAS Pioneer Hundred Talents Program and National Natural Science Foundation of China (Nos. 51809259 and 51774056).

\section{References}

1 Wang M., Zhao P., Wu Y., Dai Y. (2015) Performance analysis of a novel energy storage system based on liquid carbon dioxide, Appl. Therm. Eng. 91, 812-823. doi: 10.1016/j.applthermaleng.2015.08.081.

2 Kong Y., Pang Z., Pang J., Luo L., Luo J., Shao H.B., Kolditz O. (2015) Deep groundwater cycle in Xiongxian geothermal field, in: Proceedings of World Geothermal Congress, 19-25 April, Melbourne, Australia. https:// pangea.stanford.edu/ERE/db/WGC/papers/WGC/2015/ 15045.pdf.

3 Allis R.G. (1990) Subsidence at Wairakei field, New Zealand, TrGRC 14, 1081-1087.

4 Armienta M., Rodriguez R., Ceniceros N., Cruz O., Aguayo A., Morales P., Cienfuegos E. (2014) Groundwater quality and geothermal energy, the case of Cerro Prieto geothermal field, Mexico, Renew. Energy 63, 236-254. doi: 10.1016/j.renene. 2013.09.018.

5 Zeng Y., Wu N., Su Z., Hu J. (2014) Numerical simulation of electricity generation potential from fractured granite reservoir through a single horizontal well at Yangbajing geothermal field, Energy 65, 472-487. doi: 10.1016/j.energy. 2013.10.084.

6 Wang L. (2014) A study of geothermal reinjection in the Guantao reservoir in Tianjin, Master Thesis, China University of Geosciences, Beijing [in Chinese].

7 Seibt P., Kellner T. (2003) Practical experience in the reinjection of cooled thermal waters back into sandstone reservoirs, Geothermics 32, 733-741. doi: 10.1016/S03756505(03)00071-3.

8 Ungemach P. (2003) Reinjection of cooled geothermal brines into sandstone reservoirs, Geothermics 32, 743-761. doi: 10.1016/S0375-6505(03)00074-9.

9 Liu H., Hou Z., Were P., Sun X.L., Gou Y. (2015) Numerical studies on $\mathrm{CO}_{2}$ injection-brine extraction process in a lowmedium temperature reservoir system, Environ. Earth Sci. 73, 6839-6854. doi: 10.1007/s12665-015-4086-3.

10 Aliyu M.D., Chen H.P. (2017) Sensitivity analysis of deep geothermal reservoir: Effect of reservoir parameters on production temperature, Energy 129, 101-113. doi: 10.1016/j.energy.2017.04.091.

11 Brown D.W. (2000) A hot dry rock geothermal energy concept using supercritical $\mathrm{CO}_{2}$ instead of water, in: Proceedings of the 25th Workshop on Geothermal Reservoir Engineering, January 22-24, Stanford University, Stanford, CA, pp. 233-238.

12 Pruess K. (2006) Enhanced geothermal systems (EGS): Using $\mathrm{CO}_{2}$ as working fluid - a novel approach for generating renewable energy with simultaneous sequestration of carbon, Geothermics 35, 4, 351-367. doi: 10.1016/j.geothermics. 2006.08.002.

13 Pruess K., Azaroual M. (2006) On the feasibility of using supercritical $\mathrm{CO}_{2}$ as heat transmission fluid in an engineered hot dry rock geothermal system, in: Proceedings of the Thirty-First Workshop on Geothermal Reservoir Engineering, 30 January-1 February, Stanford University, Stanford, CA, USA, pp. 386-393. 
14 Buscheck T., Elliot T., Celia M., Chen M.J., Sun Y.W., Hao Y., Lu C.H., Wolery T., Aines R. (2013) Integrated geothermal- $\mathrm{CO}_{2}$ reservoir systems: Reducing carbon intensity through sustainable energy production and secure $\mathrm{CO}_{2}$ storage, Energy Proc. 37, 6587-6594. doi: 10.1016/j.egypro.2013. 06.591.

15 Goerke U.-J., Park C.-H., Wang W., Singh A.K., Kolditz O. (2011) Numerical simulation of multiphase hydromechanical processes induced by $\mathrm{CO}_{2}$ injection into deep saline aquifers, Oil \& Gas Sci. Technol. - Rev. IFP Energies nouvelles 66, 1, 105-118. doi: 10.2516/ogst/2010032.

16 Elliot T., Buscheck T., Celia M. (2013) Active $\mathrm{CO}_{2}$ reservoir management for sustainable geothermal energy extraction and reduced leakage, Greenh. Gases Sci. Technol. 3, 1, 50-65. doi: 10.1002 /ghg.1328.

17 Li Q., Chen Z., Zhang J.T., Liu L.C., Li X.C., Jia L. (2016) Positioning and revision of CCUS technology development in China, Int. J. Greenh. Gas Con. 46, 282-293. doi: 10.1016/j. ijggc.2015.02.024.

18 Liu H., Hou Z., Li X., Wei N., Tan X., Were P. (2015) A preliminary site selection system for a $\mathrm{CO}_{2}$-AGES project and its application in China, Environ Earth Sci. 73, 68556870. doi: 10.1007/s12665-015-4249-2.

19 Liu H., Were P., Li Q., Gou Y., Hou Z. (2017) Worldwide status of CCUS technologies and their development and challenges in China, Geofluids 2017, 25, ID 6126505. doi: $10.1155 / 2017 / 6126505$.

20 Randolf J., Saar M. (2011) Combining geothermal energy capture with geologic carbon dioxide sequestration, Geophys. Res. Lett. 38, L10401. doi: 10.1029/2011GL047265.

21 Yucetas I., Ergicay N., Akin S. (2018) Carbon dioxide injection field pilot in Umurlu Geothermal Field, Turkey, $\operatorname{Tr} G R C$ 42, 2285-2291.

22 Randolf J. (2018) $\mathrm{CO}_{2}$ plume geothermal (CPG) and the earth battery-innovative, dispatchable geothermal power production and geologic energy storage using non-water working fluids, $\operatorname{Tr} G R C$ 42, 1543-1556.

23 Ahmed W., Javed A. (2014) $\mathrm{CO}_{2}$ as a working fluid in geothermal power plants: Comparison of recent studies and future recommendations, in: Proceedings of Thirty-Ninth Workshop on Geothermal Reservoir Engineering, 24-26 February, Stanford University, Stanford, CA, SGP-TR-202.

24 Pang Z., Yang F., Duan Z., Huang T. (2008) Gas-water-rock interactions in sandstone reservoirs: Implications for enhance re-injection into geothermal reservoirs and $\mathrm{CO}_{2}$ geological sequestration, in: Workshop for Decision Makers on Direct Heating Use of Geothermal Resources in Asia, 11-18 May, Tianjin, China.

25 Gong B., Liang H., Xin S., Li K.W. (2011) Effect of water injection on reservoir temperature during power generation in oil fields, in: Proceedings Thirty-Sixth Workshop on Geothermal Reservoir Engineering, 31 January-2 February, Stanford University, Stanford, CA.

26 Gurses C., Tureyen O., Satman A. (2017) Effect of injected cold water on the bottomhole temperature behavior, in: Proceedings of 42nd Workshop on Geothermal Reservoir Engineering, 13-15 February, Stanford University, Stanford, CA, SGP-TR-212.

27 Axelsson G., Bjornsson G., Flovenz O.G., Kristmannsdottir H., Sverrisdottir G. (1995) Injection experiments in low temperature geothermal areas in Iceland, in: Proceedings of World Geothermal Congress, 18-31 May, Florence, Italy.
28 Wang K. (2005) Studies of the reinjection tests in basement geothermal reservoir, Tianjin, China, in: Proceedings of World Geothermal Congress, 24-29 April, Antalya, Turkey.

29 Ryder R.T., Qiang J., McCabe P.J., Nuccio V.F., Persits F. (2012) Shahejie/Guantao/Wumishan and Carboniferous/ Permian coal-Paleozoic total petroleum systems in the Bohaiwan Basin, China (based on geologic studies for the 2000 World Energy Assessment Project of the U.S. Geological Survey), USGS Scientific Investigation Report 20115010, U.S. Geological Survey, Reston, VA. https://pubs. usgs.gov/sir/2011/5010/pdf/SIR2011-5010.pdf.

30 Hou F., Sun S., Zhang B. (2015) Geothermal resource and development in Tianjin of China, in: Proceedings of World Geothermal Congress, 19-25 April, Melbourne, Australia.

31 Axelsson G., Dong Z. (1998) The Tanggu geothermal reservoir (Tianjin, China), Geothermics 27, 3, 271-294. doi: 10.1016/S0375-6505(98)00002-9.

32 Wang L., Lin L. (2010) Discussion on reinjection geothermal fluids into sandstones in Tianjin P.R.C., in: Proceedings of World Geothermal Congress, 25-30 April, Bali, Indonesia.

33 Lei H., Zhu J. (2013) Numerical modeling of exploitation and reinjection of the Guantao geothermal reservoir in Tanggu District, Tianjin, China, Geothermics 48, 60-68. doi: 10.1016/j.geothermics.2013.03.008.

34 Bai B., He Y.Y., Li X.C., Li J., Huang X.X., Zhu J.L. (2017) Experimental and analytical study of the overall heat transfer coefficient of water flowing through a single fracture in a granite core, Appl. Therm. Eng. 116, 79-90. doi: 10.1016/j.applthermaleng.2017.01.020.

35 Chen Y.K. (2013) Exploration of active faults in Tianjin and assessment of seismic risks, Science Press, 308 p. (in Chinese).

36 Zhang B.M. (2008) Geothermal utilization and economic development in Tianjin, in: Geothermal Trainning Programme, 30th Anniversary Workshop, 26-27 August, Orkustofnum, Reykjavik, Iceland.

37 Kaya E., Zarrouk S.J., O'Sullivan M.J. (2011) Reinjection in geothermal fields: A review of worldwide experience, Renew. Sust. Energ. Rev. 15, 47-68. doi: 10.1016/j.rser. 2010.07.032.

38 Van Genuchten M. (1980) A closed-form equation for predicting the hydraulic conductivity of unsaturated soils, Soil Sci. Soc. Am. J. 44, 892-898. doi: 10.2136/sssaj1980. 03615995004400050002x.

39 Corey A. (1954) The interrelation between gas and oil relative permeabilities, Prod. Mon. 19, 38-41.

40 Bedre M.G., Anderson B.J. (2012) Sensitivity analysis of low-temperature geothermal reservoirs: Effect of reservoir parameters on the direct use of geothermal energy, $\operatorname{Tr} G R C$ 36, $1255-1261$.

41 Diaz A.R., Kaya E., Zarrouk S.J. (2015) Reinjection in geothermal fields: A worldwide review update, in: Proceedings World Geothermal Congress, 19-25 April, Melbourne, Australia.

42 McLean K., Zarrouk S.J. (2015) Impact of cold water injection on geothermal pressure transient analysis: A reservoir modelling assessment, in: Proceedings 37th New Zealand Geothermal Workshop, 18-20 November, Taupo, New Zealand.

43 Axelsson G. (2012) Role and management of geothermal reinjection, in: Short Course on Geothermal Development and Geothermal Wells, 11-17 March, Santa Tecla, El Salvador. 
44 Nick H.M., Wolf K.H., Brhun D. (2015) Mixed $\mathrm{CO}_{2}$-water injection into geothermal reservoirs: A numerical study, in: Proceedings of World Geothermal Congress, 19-25 April, Melbourne, Australia.

45 Hanano M. (2003) Sustainable steam production in the Matsukawa geothermal field, Japan, Geothermics 32, 311-324. doi: 10.1016/S0375-6505(03)00023-3.

46 Sanyal S.K., Enedy S.L. (2011) Fifty years of power generation at the Geysers geothermal field, California - the lessons learned, in: Proceedings of Thirty-Sixth Workshop on Geothermal Reservoir Engineering, 31 January-1 February, Stanford University, Stanford, CA, USA.

47 Cappetti G., Parisi L., Ridolfi A., Stefani G. (1995) Fifteen years of reinjection in the Larderello-Valle Secolo area: analysis of the production data, in: Proceedings of World Geothermal Congress, 18-31 May, Florence, Italy.

48 Kewiy W.R. (2013) Injection and production well testing in the geothermal fields of southern Hengill and Reykjanes,
SW-Iceland and Theistareykir, N-Iceland, Geothermal Training Programme, Orkustofnun, Reykjavik, Iceland, Reports 2013, No. 31.

49 Saito H., Honda M., Tagomori K., Haruguchi K., Tsukamoto S. (2000) Pressure changes in reinjection wells and gravity changes in Otake geothermal field, Japan, in: Proceedings of World Geothermal Congress, 28 May-10 June, KyushuTohoku, Japan.

50 Liu J., Wang K. (2006) Geothermal reinjection in China, in: Proceedings of the 7th Asian Geothermal Symposium, 2526, July, Qingdao, China.

51 Zhao N., Wang G.H., Feng W.X., Li Y.Y., Gao L. (2015) Reinjection effect study of different geothermal well completion in porous sandstone reservoir in Tianjin, China, in: Proceedings of World Geothermal Congress, 19-25 April, Melbourne, Australia. 